\title{
Silício na mitigação dos estresses por deficiência de manganês e pelo déficit hídrico em mudas pré-brotadas de cana-de-açúcar (Revisão Bibliográfica)
}

\author{
Silicon to mitigate stress due to manganese deficiency and water deficit in \\ pre-sprouted sugarcane seedlings \\ (Bibliographic Review)
}

\begin{abstract}
Gelza Carliane Marques TEIXEIRA ${ }^{1}$; Antonio Márcio Souza ROCHA ${ }^{2}$; Kamilla Silva OLIVEIRA ${ }^{3}$; Marcilene Machado dos Santos SARAH ${ }^{4}$; Antonio Santana Batista de OLIVEIRA FILHO; Luiz Fabiano PALARETTI ${ }^{7}$
\end{abstract}

${ }^{1}$ Autor para correspondência, Mestra, Universidade Estadual Paulista “Júlio de Mesquita Filho" (UNESP), Faculdade de Ciências Agrárias e Veterinárias (FCAV), Departamento de Ciências da Produção Agrícola, Setor de Solos e Adubos, Via de Acesso Prof. Paulo Donato Castellane s/n, 14884-900, Brasil, gelzacarliane@hotmail.com

${ }^{2}$ Mestre, Universidade Estadual Paulista "Júlio de Mesquita Filho" (UNESP), Faculdade de Ciências Agrárias e Veterinárias (FCAV), Departamento de Tecnologia, Via de Acesso Prof. Paulo Donato Castellane s/n, 14884-900, Brasil, antoniomarcio.sr@gmail.com

${ }^{3}$ Mestra, Universidade Estadual Paulista "Júlio de Mesquita Filho" (UNESP), Faculdade de Ciências Agrárias e Veterinárias (FCAV), Departamento de Ciências da Produção Agrícola, Setor de Solos e Adubos, Via de Acesso Prof. Paulo Donato Castellane s/n, 14884-900, Brasil, millah_oliveira15@hotmail.com

${ }^{4}$ Mestra, Universidade Estadual Paulista "Júlio de Mesquita Filho" (UNESP), Faculdade de Ciências Agrárias e Veterinárias (FCAV), Departamento de Engenharia e Ciências Exatasl, Via de Acesso Prof. Paulo Donato Castellane s/n, 14884-900, Brasil, marcilene.m.sarah@gmail.com

${ }^{5}$ Engenheiro-Agrônomo, Universidade Estadual Paulista “Júlio de Mesquita Filho" (UNESP), Faculdade de Ciências Agrárias e Veterinárias (FCAV), Departamento de Ciências da Produção Agrícola, Setor de Solos e Adubos, Via de Acesso Prof. Paulo Donato Castellane s/n, 14884-900, Brasil, a15santanafilho@gmail.com

${ }^{6}$ Doutor, Universidade Estadual Paulista "Júlio de Mesquita Filho" (UNESP), Faculdade de Ciências Agrárias e Veterinárias (FCAV), Departamento de Ciências da Produção Agrícola, Setor de Solos e Adubos, Via de Acesso Prof. Paulo Donato Castellane s/n, 14884-900, Brasil, rm.prado@unesp.br

${ }^{7}$ Doutor, Universidade Estadual Paulista "Júlio de Mesquita Filho" (UNESP), Faculdade de Ciências Agrárias e Veterinárias (FCAV), Departamento de Engenharia e Ciências Exatas, Via de Acesso Prof. Paulo Donato Castellane s/n, 14884-900, Brasil, luiz.f.palaretti@unesp.br

Recebido em: 17-03-2020; Aceito em: 09-04-2020

\section{Resumo}

Foi realizada revisão bibliográfica sobre os benefícios do silício (Si) em atenuar estresses a nível fisiológico e nutricional em mudas pré-germinadas (MPB) de cana-de-açúcar submetidas aos estresses por deficiência nutricional e por déficit hídrico. Ficou evidente que o Si pode ser utilizado para amenizar os danos causados pela deficiência de micronutrientes, como o manganês $(\mathrm{Mn})$, porque diminui os danos causados pelo estresse e incrementa o acúmulo de massa seca. E ainda, que o Si pode potencializar as adubações com Mn, aumentando a resposta das plantas mesmo na suficiência do micronutriente, porque atua em locais semelhantes ao $\mathrm{Mn}$ no metabolismo das plantas. Também foi demonstrado que o fornecimento de Si na fase de formação de MPB ou depois do transplantio via fertirrigação, proporciona efeitos benéficos que contribuem para manter o conteúdo de água no tecido foliar e diminuir os danos causados pelo déficit hídrico, proporcionando maior produção de massa. E isso ocorre, mesmo quando as mudas são submetidas a diferentes intensidades de déficit hídrico, na fase inicial de desenvolvimento e na rebrota da soqueira, em espécies de cana-de-açúcar (Saccharum officinarum L. e Saccharum spontaneum $\mathrm{L}$.) diferentes quanto à tolerância à seca e quando cultivadas em diferentes tipos de solo. Em conclusão, o fornecimento de Si em MPB de cana-de-açúcar deve ser considerado uma nova estratégia de manejo nos sistemas de produção porque pode aumentar a tolerância à diversos estresses e assim, aumentar a produtividade das áreas destinadas ao cultivo de cana-de-açúcar.

Palavras-chave adicionais: deficiência hídrica; desordem nutricional; elemento benéfico; estresse abiótico; nutrição de plantas; Saccharum spp.

\section{Abstract}

A bibliographic review was carried out on the benefits of silicon (Si) in alleviating stress at the physiological and nutritional level in pre-sprouted sugarcane seedlings (PSS) submitted to stress due to nutritional deficiency and water deficit. It was evident that Si can be used to mitigate the damage caused by micronutrient deficiency, such as manganese $(\mathrm{Mn})$, because it reduces the damage caused by stress and increases the accumulation of dry matter. 
And yet, that $\mathrm{Si}$ can potentiate fertilizations with $\mathrm{Mn}$, increasing the response of plants even in the sufficiency of the micronutrient, because it acts in places similar to $\mathrm{Mn}$ in the metabolism of plants. It has also been shown that the supply of $\mathrm{Si}$ in the MPB formation phase or after transplantation via fertigation, provides beneficial effects that contribute to maintaining the water content in the leaf tissue and reducing the damage caused by water deficit, providing greater matter production. And this occurs, even when the seedlings are subjected to different intensities of water deficit, in the initial stage of development and in the regrowth of the knuckle, in different types of sugarcane (Saccharum officinarum L. and Saccharum spontaneum L.) drought tolerance and when grown in different soil types. In conclusion, the supply of Si in sugarcane MPB should be considered a new management strategy in production systems because it can increase the tolerance to various stresses and thus, increase the productivity of areas destined to the cultivation of sugarcane.

Additional keywords: abiotic stress; beneficial element; nutritional disorder; plant nutrition; Saccharum spp.; water deficiency.

\section{Introdução}

A produção global de cana-de-açúcar (Saccharum spp.) aumentou devido a sua importância como fonte de energia renovável (Matsuoka, 2017). No entanto, a cana-de-açúcar é comumente exposta à condições de restrições ambientais, como a seca, que é o principal fator abiótico que causa perdas de produtividade na cultura (Basnayake et al., 2012), especialmente quando ocorre durante os estágios iniciais de desenvolvimento (Machado et al., 2009), e quando são utilizados mudas obtidas pelo sistema de mudas-prébrotadas (MPB) (Martins et al., 2015).

Atualmente, nas áreas de cultivo de cana-deaçúcar, tem-se utilizado o sistema MPB que consiste na individualização das gemas do colmo da cana-de-açúcar e o seu plantio em um tubete para prévia germinação ao transplantio no campo (Landell et al., 2012). A adoção dessa técnica tem permitido a diminuição do volume de colmos por hectare; o aumento da taxa de multiplicação, da sanidade das mudas e da uniformidade do plantio; e o uso de menor volume de material no campo, com aumento na operacionalidade do plantio (Gírio et al., 2015).

Contudo, as mudas são transplantadas já com área foliar e sem as reservas de nutrientes e água advindas do colmo, o que agrava a sensibilidade à seca de mudas recém-transplantada para o campo (Martins et al., 2015). Este aspecto ganha importância pelo fato de que parte do plantio das MPB ocorre em épocas do ano com baixa pluviosidade. Soma-se a isso, a limitação nutricional que também pode prejudicar a produção de cana-de-açúcar, porque plantas cultivadas sob fertilidade inadequada diminuem o seu potencial produtivo (Prado, 2020).

Entre as deficiências nutricionais a de micronutriente, como o manganês ( $\mathrm{Mn}$ ), é a mais comum em áreas de cultivo de cana-de-açúcar porque a cultura geralmente é plantada em solos arenosos e muito lixiviados, bem como, em solos que a calagem é realizada de forma inadequada, seja pela má incorporação do calcário ou por sua aplicação em doses excessivas (Sultanum, 1972). Assim, a busca por estratégias de manejo que visam diminuir as perdas no transplantio, como a nutrição com silício (Si), que é um elemento benéfico que atenua múltiplos estresses (Vasanthi et al., 2014), podem ser eficientes para melhorar a tolerância das MPB e diminuir as falhas no campo, refle- tindo em aumento da produtividade e vida útil do canavial.

O Si beneficia a cana-de-açúcar em déficit hídrico por mitigar os danos causados pelo estresse, atuando em processos fisiológicos e bioquímicos, como na manutenção do potencial hídrico foliar (Pei et al., 2010) e do conteúdo de água (Liu et al., 2014), na modificação dos atributos de trocas gasosas como a assimilação de $\mathrm{CO}_{2}$ e as taxas de transpiração (Farooq \& Dietz, 2015), na preservação de pigmentos fotossintéticos (Bokhtiar et al., 2012), no ajuste de osmólitos compatíveis (Bezerra et al., 2019), na diminuição do estresse oxidativo (Gong et al., 2005), beneficiando as variáveis de crescimento e a produção de massa seca.

Além disso, o Si também possui potencial para diminuir os danos causados por desordens nutricionais, onde tem sido verificado que a aplicação do elemento tem atenuado os sintomas por melhorar a redistribuição do nutriente, em plantas deficientes em ferro ( $\mathrm{Fe}$ ) (Bityutskii et al., 2014), por melhorar a eficiência de uso de micronutrientes, como o Mn (Oliveira et al., 2019) e - Fe (Teixeira et al., 2020a), e por aumentar o crescimento (Timotiwu et al., 2017) e a produtividade de plantas da família Poaceae, como milho e sorgo na deficiência de Mn (Oliveira et al., 2020).

No entanto, os efeitos do Si em MPB ainda são pouco descritos em trabalhos científicos publicados. Um estudo pioneiro foi realizado avaliando dois métodos de fornecimento de Si solúvel em MPB (via radicular e via pulverização foliar) e seus efeitos residuais na mitigação do déficit hídrico em plantas aos 30 dias após o transplantio no solo (Teixeira et al., 2020b). Os autores concluíram que fornecimento de $\mathrm{Si}$ proporciona um efeito benéfico que contribui para diminuir os danos causados pelo déficit hídrico após o transplantio das mudas para o campo, por melhorar variáveis fisiológicas e aumentar a produção de massa seca, e que a aplicação via radicular é mais viável em relação a pulverização foliar.

Desse modo, o GENPLANT (Grupo de Estudos em Nutrição de Plantas da Unesp) em parceira com o GPIMA (Grupo de Pesquisa em Irrigação e Meio Ambiente) têm desenvolvido trabalhos com o intuito de avaliar o uso do Si na mitigação dos danos causados por estresses de natureza abiótica em MPB, como a deficiência nutricional e o déficit hídrico, em espécies de cana-de-açúcar (Saccharum officinarum L. e 
Saccharum spontaneum L.), avaliadas ao longo das fases de desenvolvimento da cultura e cultivadas em diferentes solos. E assim, os principais resultados obtidos nesses trabalhos são apresentados nesta revisão bibliográfica.

\section{Uso de mudas pré-brotadas de cana-de-açúcar}

O Brasil é maior produtor mundial de cana-de-açúcar, sendo a cultura considerada uma das grandes alternativas para o setor de biocombustíveis devido ao grande potencial na produção de etanol e seus subprodutos. A produção sucroalcoleira do Brasil é favorecida tanto pelas características potenciais à produção de energia que a própria cultura possui, quanto pela existência de grandes áreas cultiváveis e condições edafoclimáticas favoráveis (Matsuoka, 2017).

Atualmente, áreas destinadas ao cultivo de cana-de-açúcar, sobretudo no estado de São Paulo, têm utilizado o sistema de produção de mudas prébrotadas (MPB) para a reforma dos canaviais. Nesse sistema, as mudas são produzidas em núcleos específicos de produção (biofábricas) a partir da individualização de gemas que são plantadas em tubetes contendo substrato. Durante a fase de formação das mudas, tem-se um alto rigor nutricional, com os nutrientes fornecidos, geralmente, via fertirrigação (Landell et al., 2012).

As vantagens de se utilizar esse sistema são inúmeras, e dentre elas, destaca-se a diminuição do volume de colmos por hectare utilizado na reforma do canavial, que é proporcionada pelo aumento da taxa de multiplicação. Estima-se que seja necessário a utilização de apenas $1 \mathrm{Mg}$ de colmos para produzir mudas para o plantio de 1 hectare. Isso representa um aumento de até $19 \mathrm{Mg}$ na quantidade de colmos destinados a produção, seja de açúcar ou etanol, considerando que o sistema convencional utiliza geralmente $20 \mathrm{Mg} \mathrm{ha}^{-1}$ de colmo (Xavier et al., 2013). A diminuição da quantidade de colmo também permite maior rigor no manejo sanitário, formando mudas de maior qualidade e vigor vegetativo, possibilitando a obtenção de um canavial mais sadio e uniforme. Além disso, tem-se maior operacionalidade durante o plantio, diminuindo o tráfego de máquinas, a compactação do solo e os custos financeiros com a prática agrícola (Gírio et al., 2015).

Assim, o sistema de produção de cana-de-açúcar através do uso de MPB tem sido considerado uma alternativa promissora para o aumento da produção de álcool e açúcar nas áreas já cultivadas, diminuindo a pressão pela abertura de novas áreas de cultivo e, consequentemente, preservando os recursos naturais em áreas de vegetação nativa (Santos et al., 2020). Contudo, ainda existem alguns fatores que podem comprometer a eficiência na utilização dessa técnica, que estão especialmente relacionados a disponibilidade hídrica após o transplantio e a deficiências nutricionais.
Escassez de água durante a fase inicial de desenvolvimento pode comprometer o vigor vegetativo e a produtividade da cultura, além de ser um fator determinante na fase de transplantio das mudas para o campo. A sensibilidade de mudas obtidas pelo sistema MPB na fase de transplantio é muito intensa porque as plantas são levadas à campo já com área foliar, que permite a perda de água por transpiração, e diferente do sistema convencional, a reserva de água e energia fornecida pelo colmo foi removida (Landell et al., 2012). Essa limitação, aliada aos cenários futuros das mudanças climáticas, pode comprometer a viabilidade de utilização dessa técnica, se não houver um fortalecimento nutricional das mudas produzidas.

Somam-se a isso, as limitações causadas por deficiências nutricionais, sobretudo, as de micronutrientes como o manganês (Mn), que são frequentes em áreas destinadas ao cultivo de cana-de-açúcar. $\mathrm{Na}$ deficiência deste micronutriente, há queda na produção de compostos fenólicos e lignina (Lidon et al., 2004; Malavolta, 2006), sendo estes dois componentes importantes para a produção da cana-convencional (Saccharum officinarum L.) e da cana-energia (Saccharum spontaneum L.), pois maiores conteúdos de lignina são preferíveis para a produção de energia elétrica porque facilitam a queima da biomassa vegetal (Carvalho-Netto et al., 2014). No entanto, apesar dos comprovados ganhos ocasionados pela adição de micronutrientes na adubação de cana-de-açúcar, ainda faltam pesquisas no Brasil e no mundo que abordem esta prática.

Desse modo, a utilização de estratégias que visem diminuir as perdas na fase subsequente ao transplantio das mudas à campo podem ser eficientes para o aumento do uso de MPB, aumentando a produtividade e a vida útil do canavial, a partir da atenuação dos efeitos causados pelo déficit hídrico e por desordens nutricionais. Neste cenário insere-se o silício (Si), um elemento benéfico que contribui para atenuar os danos causados por estresses ambientais. No entanto, o efeito da aplicação de Si em mudas prébrotadas ainda é incipiente, fazendo-se necessária a realização de pesquisas para esclarecer se o acúmulo do elemento no tecido foliar proporciona efeito mitigador dos danos provocados por estresses ambientais de natureza biótica, como as desordens nutricionais e o déficit hídrico.

\section{Silício na mitigação de estresses abióticos em mudas pré-brotadas de cana-de-açúcar}

\subsection{Papel do silício na supressão dos danos causados} pela deficiência de manganês

O silício (Si) é um elemento que se destaca pela ampla capacidade de minimizar os danos causados por estresses em plantas. Muito se tem investigado para conhecer os meios de atuação deste elemento na melhoria do desempenho das culturas frente a adversidades, seja de origem biótica ou abiótica, e estimular o crescimento e desenvolvimento de várias espécies vegetais (Liang et al., 2007). 
Um dos fatores estressores de natureza abiótica em plantas é a deficiência nutricional, visto que, plantas sob condições de fertilidade inadequadas sofrem diminuição do seu potencial produtivo ocasionada pelo comprometimento de suas funções metabólicas acarretando desordens fisiológicas que comprometem o alcance da produtividade desejada (Prado, 2020).

A deficiência de manganês $(\mathrm{Mn})$ frequentemente caracteriza-se pelo sintoma de "fome oculta" nas culturas, que é a ocorrência de deficiência e diminuição da produção sem, no entanto, apresentar sintoma visual, fato recorrente em cana-de-açúcar em relação aos micronutrientes, incluindo o Mn (Mellis et al., 2008). A deficiência de Mn em cana-de-açúcar, geralmente, se apresenta em solos arenosos e muito lixiviados, e em solos com correção inadequada da acidez, seja pela má incorporação do calcário ou pela sua aplicação em doses excessivas (Sultanum, 1972). Atualmente, os solos que estão sendo ocupados por cultivos de cana-de-açúcar, em sua maioria apresentam baixos níveis deste micronutriente, resultado de cultivos sucessivos e perdas por erosão, além da falta de reposição de nutrientes (Mellis et al., 2008).

As funções exercidas pelo $\mathrm{Mn}$ nas plantas são diversas, como transportador de elétrons na fotossíntese, como cofator da fotólise da água no fotossistema II (FSII) (Millaleo et al., 2010), e ainda, é responsável pela ativação de mais de 35 enzimas envolvidas em reações de oxidação, carboxilação, metabolismo de carboidratos, reações com fósforo e no ciclo do ácido cítrico (Mousavi et al., 2011). O Mn também exerce papel importante no metabolismo antioxidante sendo cofator da superóxido dismutase (SOD), uma enzima responsável pela eliminação dos radicais livres, colaborando para diminuir os danos causados pelo estresse oxidativo (Millaleo et al., 2010). Além disso, o micronutriente participa da síntese de ATP (Pfeffer et al., 1986), da biossíntese de clorofila, compostos fenólicos, aminoácidos aromáticos, lignina e flavonoides (Lidon et al., 2004; Malavolta, 2006) e na assimilação do nitrato (Ducic \& Polle, 2005).

O Mn também está envolvido na rota metabólica de biossíntese dos metabólitos secundários, onde o primeiro passo é a síntese de 3-Deoxi-D-arabinoheptulosonato-7-fosfato (DAHP), que é catalisada pela enzima DAHP-sintase, que exige Mn para sua ativação. Ainda dentro da rota de síntese de metabólitos secundários, o Mn atua na atividade da enzima fenilalanina amônia liase (PAL), que catalisa a desaminação da fenilalanina em ácido cinâmico, um precursor de compostos flavonóides incluindo as antocianinas. Este caminho também leva a uma gama de produtos secundários como cumarinas, fenóis e ligninas (Burnell, 1988).

Para a cana-de-açúcar, o Mn é o segundo micronutriente mais extraído e exportado (Orlando Filho, 1993), demonstrando a sua importância para a cultura. Em trabalho de Mellis et al. (2016), analisando aplicação de micronutrientes em cana-de-açúcar, foi observado que o fornecimento de $\mathrm{Mn}$ incrementou a produtividade da cultura, alcançando ganho de $12 \mathrm{Mg} \mathrm{ha}^{-1}$, sendo igual à produtividade ocasionada pelo molibdênio e ficando atrás apenas da proporcionada pelo zinco.

O Mn torna-se ainda mais importante para a cana-de-açúcar quando o cultivo destina-se a produção de bioenergia, porque quando são submetidas a condição de deficiência de Mn, tanto a cana-de-açúcar convencional (Saccharum officinarum L.) quanto a cana-energia (Saccharum spontaneum L.), diminuem a produção de compostos fenólicos e lignina (Lidon et al., 2004; Malavolta, 2006), componentes fundamentais para o processo industrial de produção de energia elétrica, por facilitarem a combustão da biomassa vegetal (Carvalho-Netto et al., 2014). Apesar, dos comprovados benefícios ocasionados pela adição de micronutrientes na adubação de cana-de-açúcar, ainda faltam pesquisas no Brasil e no mundo que abordem esta prática, inclusive, com formas de potencializá-la.

Uma das formas de potencializar as adubações com micronutrientes é combinar as suas aplicações com a adição de Si. Isso ocorre porque tem sido verificado que esse elemento benéfico melhora o metabolismo das plantas submetidas a estresses causados por desordens nutricionais, como a deficiência de $\mathrm{Fe}$, onde plantas de sorgo apresentaram aumento da eficiência de uso deste micronutriente (Teixeira et al., 2020a). E pela deficiência de $\mathrm{Mn}$, com aumento da redistribuição de Mn em plantas de pepino (Bityutskii et al., 2014), da eficiência de uso de $\mathrm{Mn}$ em plantas de sorgo (Oliveira et al., 2019) e do rendimento de plantas de milho e sorgo (Oliveira et al., 2020).

$\mathrm{O}$ Si ainda tem sido associado à melhorias do sistema antioxidante das plantas sob estresses causados por deficiência de micronutrientes (Felisberto, 2018; Oliveira et al., 2019). Como visto em plantas de sorgo sob deficiência de Mn, que a aplicação de Si tanto por via radicular quanto por via pulverização foliar diminuiu os danos causados pela deficiência de Mn por aumentar a atividade de enzimas do sistema antioxidantes e, assim, diminuiu a peroxidação lipídica, aumentou a taxa fotossintética e a eficiência de uso de $\mathrm{Mn}$, refletindo em maior produção de massa seca (Oliveira et al., 2019).

Além do efeito no sistema antioxidante, o Si ainda pode contribuir na diminuição dos sintomas de deficiência de micronutrientes, por manter a integridade dos pigmentos fotossintetizantes, como a clorofila e carotenoides, visto em plantas submetidas a deficiência de Fe (Teixeira et al., 2020a; Gonzalo et al., 2013; Pavlovic et al., 2013), de Mn (Bityutskii et al., 2014) e de zinco (Zn) (Pascual et al., 2016), e assim melhorar a atividade do FSII e aumentar a taxa fotossintética (Gonzalo et al., 2013).

Portanto, nota-se que o Si participa de rotas metabólicas semelhantes ao $\mathrm{Mn}$, podendo atuar de forma sinérgica na melhoria do desenvolvimento e produtividade da cana-de-açúcar e da cana-energia, potencializando as adubações com esse micronutriente. Desse modo, diante da necessidade da realização de pesquisas que demonstrem os efeitos dos elementos em conjunto em culturas, o GENPLANT avaliou o papel do Si na supressão dos danos causados pela deficiência de Mn em MPB de cana-de-açúcar e de cana-energia. 
Foi realizado um trabalho com o objetivo de avaliar os efeitos do Si no desenvolvimento de MPB de cana-de-açúcar (RB 966928) e de cana-energia (VX3) sob deficiência e suficiência de Mn por um período de quatro meses. Para isso, as mudas foram cultivadas em areia com aplicação de solução nutritiva via radicular, sendo a condição de suficiência de $\mathrm{Mn}$ definida segundo a recomendação de Hoagland e Arnon (1950) e a deficiência de $\mathrm{Mn}$ composta pela mesma solução, mas com ausência de $\mathrm{Mn}$. O Si foi fornecido na concentração de $2 \mathrm{mmol} \mathrm{L}^{-1}$ utilizando o silicato de sódio e potássio estabilizado com sorbitol como fonte, e as plantas foram avaliadas a partir de análises de crescimento e fisiologia.

Nas plantas não fertilizadas com $\mathrm{Si}$, o acúmulo do elemento foi baixo tanto para cana-de-açúcar (Figura 1a) quanto para cana-energia (Figura 2a). No entanto, plantas suplementadas com $\mathrm{Si}$ obtiverem maiores acúmulos em ambas as espécies, podendo ser explicados pela alta demanda e capacidade de absorção de Si pela cultura através das raízes (Yan et al., 2018) pela presença de transportadores específicos de Si que modulam a absorção e transporte para a parte aérea (Mitani et al., 2008).
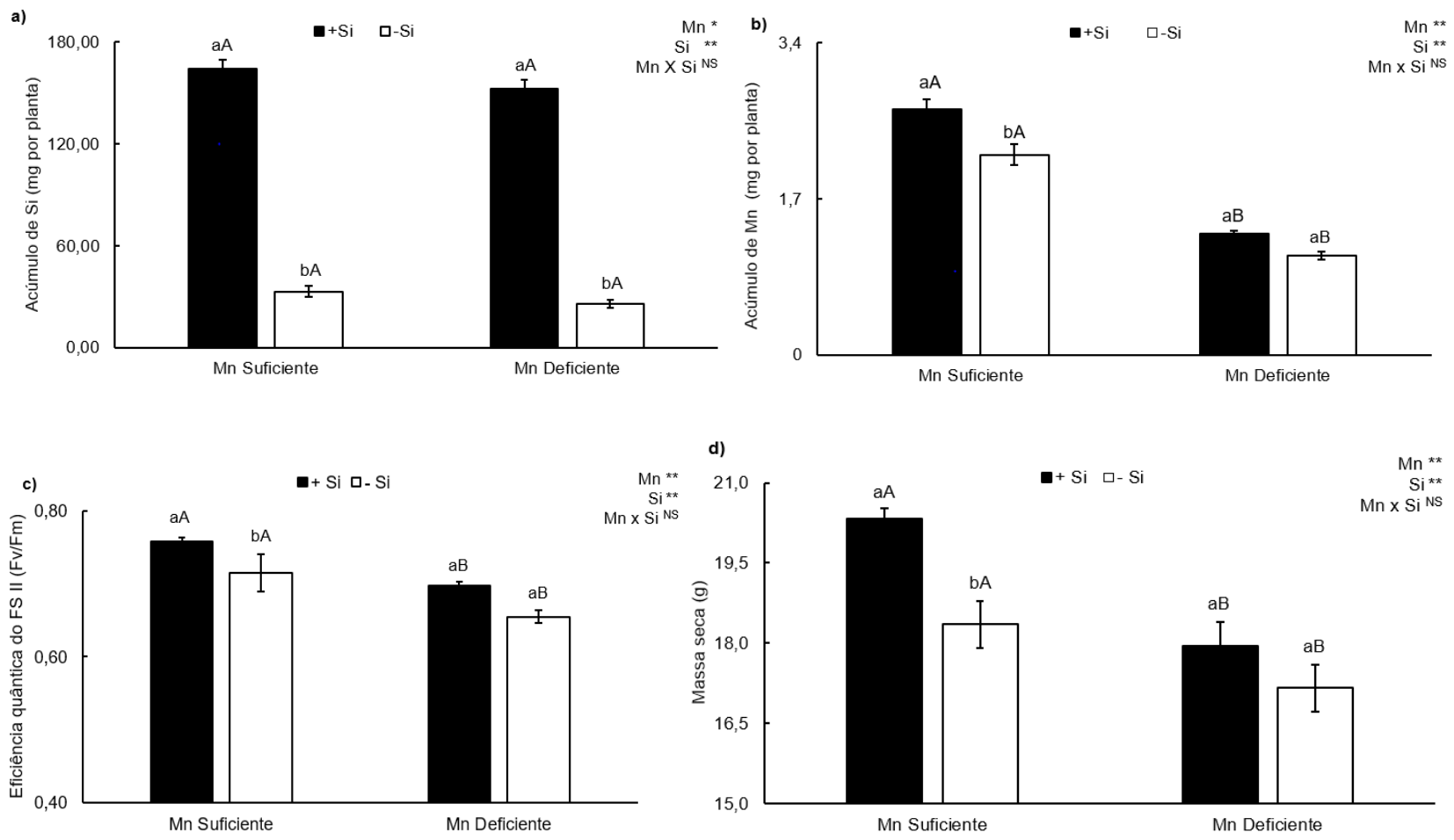

Figura 1 - Acúmulo de silício (Si) (a), acúmulo de manganês (Mn) (b), eficiência quântica do fotossistema II (FSII) (c) e massa seca (d) de plantas de cana-de-açúcar convencional (Saccharum officinarum L.) submetidas a suficiência e deficiência de Mn, na ausência (-Si) e presença (+Si) de Si aplicado via solução nutritiva. **significativo a $1 \%$ de probabilidade; * significativo a $5 \%$ de probabilidade $e^{\text {ns }}$ não significativo pelo teste $F$.

Letras minúsculas comparam condições de Si na mesma condição de Mn e letras maiúsculas comparam condições de Mn na mesma condição de $\mathrm{Si}(\mathrm{p}<0,05$, pelo teste de Tukey). As barras representam o erro padrão da média, $n=5$. Fonte: Oliveira et al. (dados não publicados).

O acúmulo de Mn em cana-de-açúcar foi maior em plantas suplementadas com o micronutriente (Figura 1b) e na presença do Si, o mesmo ocorreu em plantas de cana-energia (Figura 2b). Este efeito se deve ao fato de que o Si melhora a captação dos nutrientes pelas plantas, sobretudo, em plantas da família da Poaceae, como milho e trigo (Greger et al., 2018) e sorgo (Oliveira et al., 2019) devido à melhoria da disponibilidade do nutriente e sua absorção pela planta.

Em plantas de cana-energia, o Si beneficiou o acúmulo de $\mathrm{Mn}$ em plantas deficientes no micronutriente, o que também foi observado por Oliveira et al. (2020) em plantas de sorgo e milho na deficiência de Mn e por Pavlovic et al. (2013) e Bityutskii et al. (2014) em pepino na deficiência de Fe explicados pela melho- ria na distribuição do micronutriente na planta, inclusive do nutriente absorvidos previamente a imposição da deficiência, como observado por Pavlovic et al. (2013).

Plantas suplementadas com Mn apresentaram maior eficiência quântica do FSII, em relação às plantas deficientes em Mn. A eficiência quântica do FSII também foi melhorada pela presença de Si em plantas de cana-de-açúcar apenas na condição de suficiência de Mn (Figura 1c) e em plantas de cana-energia isso ocorreu tanto na suficiência quanto da deficiência de $\mathrm{Mn}$ (Figura 2c). A melhoria mediada pelo Si em plantas de cana-energia deve-se ao aumento no acúmulo de $\mathrm{Mn}$ (Figura 2b), que é o nutriente responsável pela manutenção do transporte de elétrons entre os fotossistemas e prevenção da fotoinibição do FSII na etapa 
fotoquímica da fotossíntese (Schmidt et al., 2016). Soma-se a isso, a atuação do Si na ativação de enzimas do sistema antioxidante de defesa das plantas, que diminui a degradação das membranas dos pigmentos fotossintéticos, como a clorofila e os carotenoides, atenuando os danos ao FSIl (Gong et al.,
2012; Cao et al., 2015). Também foi observado efeito benéfico do Si na manutenção do funcionamento do FSIl em plantas de sorgo e milho, submetidas a deficiência de Mn (Oliveira et al., 2020).
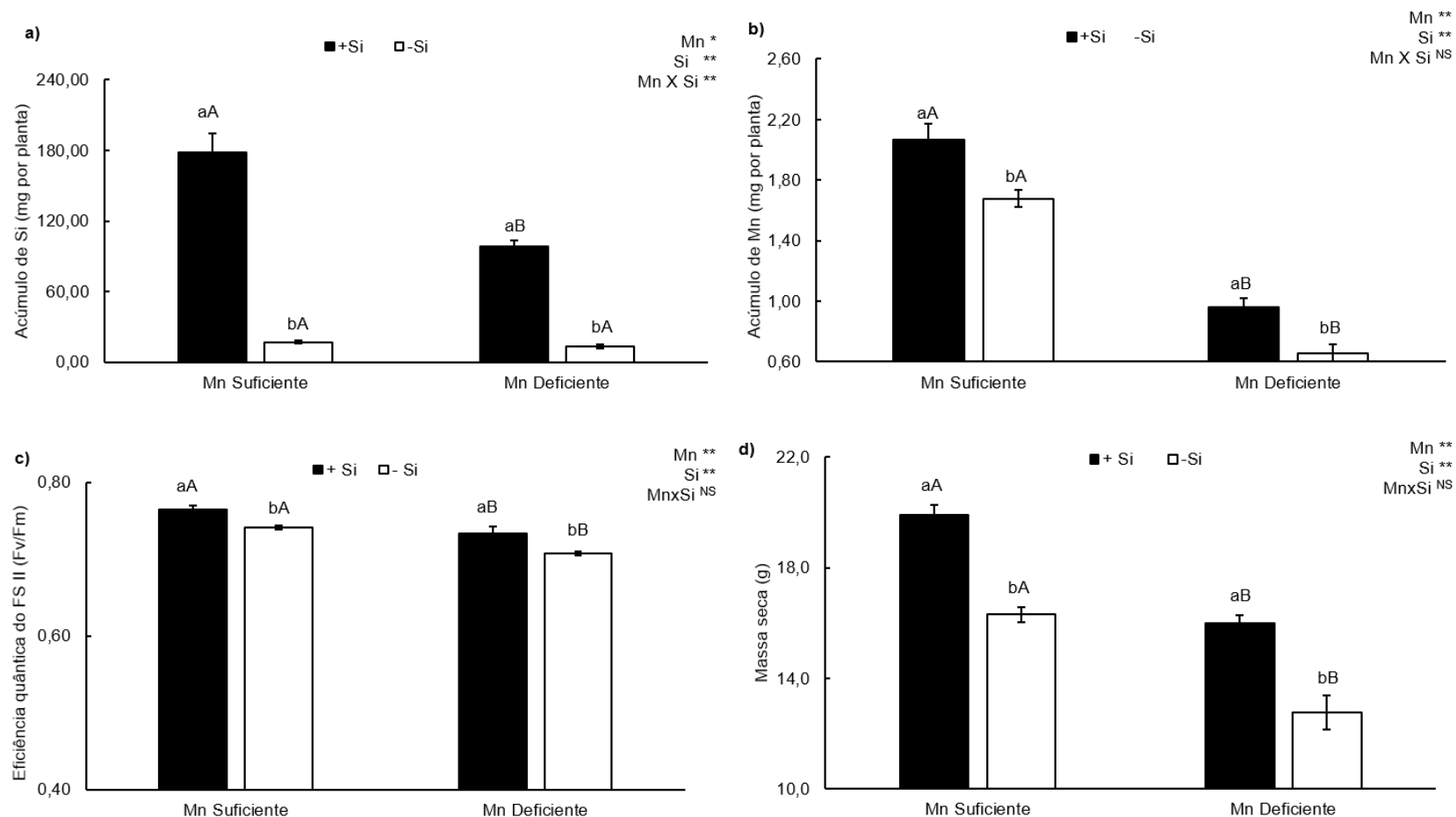

Figura 2 - Acúmulo de silício (Si) (a), acúmulo de manganês (Mn) (b), eficiência quântica do fotossistema II (FSII) (c) e massa seca (d) de plantas de cana-energia (Saccharum spontaneum L.) submetidas a suficiência e deficiência de Mn, na ausência (-Si) e presença (+Si) de Si aplicado via solução nutritiva. ${ }^{* *}$ significativo a $1 \%$ de probabilidade; * significativo a $5 \%$ de probabilidade $\mathrm{e}^{\text {ns }}$ não significativo pelo teste $\mathrm{F}$.

Letras minúsculas comparam condições de Si na mesma condição de Mn e letras maiúsculas comparam condições de Mn na mesma condição de $\mathrm{Si}$ ( $\mathrm{p}<0,05$, pelo teste de Tukey). As barras representam o erro padrão da média, $n=5$. Fonte: Oliveira et al. (dados não publicados).

$\mathrm{Na}$ ausência de $\mathrm{Si}$, as plantas de cana-deaçúcar e cana-energia deficientes em Mn tiveram as maiores perdas na produção de massa seca (Figura 1d e 2d). Mas o Si proporcionou incremento de $11 \%$ na massa seca em plantas de cana-de-açúcar suficientes em $\mathrm{Mn}$, em relação à sua ausência. No entanto, não influenciou a massa seca de plantas deficientes em Mn. Contudo, em cana-energia, o Si incrementou a massa seca de plantas deficientes em Mn (25\%) (Figura 2d), demonstrando efeitos benéficos no alívio dos danos causados pela deficiência de $\mathrm{Mn}$, isto está relacionado com uma melhoria na eficiência quântica do FSII (Figura 2c) com benefícios no processo fotossintético e ganhos de produção (Gong et al., 2012; Cao et al., 2015). Os mesmos benefícios do Si no incremento à produção de poáceas na deficiência de $\mathrm{Mn}$ foram observados por Timotiwu et al. (2017) e em plantas de milho e sorgo por Oliveira et al. (2020).

Portanto, pode-se concluir que o Si via radicular é capaz de amenizar os danos causados pela deficiência de $\mathrm{Mn}$ em plantas de cana-energia e meIhorar o crescimento em condições estressantes, inclusive de deficiência nutricional. $\mathrm{E}$ ainda, que o Si pode potencializar as adubações com Mn em cana-deaçúcar e cana-energia, aumentando a resposta das plantas mesmo na suficiência do micronutriente, visto que ambos, atuam em locais semelhantes no metabolismo das plantas. Desse modo, a nutrição conjunta destes dois elementos pode proporcionar ganhos para a cana-de-açúcar e cana-energia, melhorando o rendimento da cultura em solos que apresentem deficiência ou até mesmo solos com concentrações ideais do micronutriente.

3.2. Papel do silício na supressão dos danos causados pelo déficit hídrico

3.2.1. Silício mitiga os efeitos do déficit hídrico em espécies de cana-de-açúcar

A produção global de cana-de-açúcar aumentou significativamente devido à sua importância como fonte de energia renovável com uso na produção de álcool e também de açúcar. Além disso, o setor 
sucroalcooleiro tem ampliado sua produção para cogeração de energia elétrica a partir do bagaço da cana-deacúcar convencional (Saccharum officinarum $L$.) e mais recentemente da promissora cana-energia (Saccharum spontaneum L.) que possui maior conversão energética comparada à cana-convencional, pela elevada produção de matéria seca por área e maior teor de fibras totais (Matsuoka, 2017).

No entanto, por ser uma cultura semi-perene, a cana-de-açúcar é comumente exposta à condições de restrições ambientais, como a seca, que é o principal fator abiótico que causa perdas de produtividade na cultura (Basnayake et al., 2012), especialmente quando ocorre durante os estágios iniciais de desenvolvimento (Jain et al., 2015) e quando são usados mudas obtidas pelo sistema de produção de MPB, por haver diminuição das reservas de nutrientes e água para a planta recém-transplantada no campo (Martins et al., 2015). Na fase de transplantio, as MPB são muito sensíveis ao déficit hídrico podendo morrer, causando baixa densidade populacional no campo.

Uma estratégia para diminuir os efeitos do déficit hídrico das MPB é o uso do Si pois é conhecido seu benefício na atenuação deste estresse em várias espécies. Na cultura da cana-de-açúcar ocorre porque o Si atua em processos fisiológicos e bioquímicos, como na manutenção do potencial hídrico foliar (Pei et al., 2010) e do conteúdo de água (Liu et al., 2014), na modificação dos atributos de trocas gasosas como a assimilação de $\mathrm{CO}_{2}$ e as taxas de transpiração (Farooq \& Dietz, 2015), na preservação de pigmentos fotossintéticos (Bokhtiar et al., 2012), no ajuste de osmólitos compatíveis (Bezerra et al., 2019), na diminuição do estresse oxidativo (Gong et al., 2005), beneficiando as variáveis de crescimento e a produção de massa seca.

O efeito benéfico do Si em plantas da família Poaceae, como a cana-de-açúcar, são mais acentuados porque essas plantas acumulam grandes quantidades do elemento em seus tecidos foliares, sendo consideradas acumuladoras por possuírem transportadores específicos que atuam na absorção e no transporte de Si das raízes para a parte aérea (Mitani et al., 2008). Dessa forma, ocorre uma deposição de Si no apoplasto foliar, formando uma camada dupla de sílicacutícula nas células epidérmicas da folha (Lux et al., 2002; Pei et al., 2010), que colabora diminuindo as perdas de água pela folha, melhorando a arquitetura foliar e proporcionando maior resistência a danos mecânicos (Ma \& Yamaji, 2015).

No sistema de produção de MPB, as mudas são cultivadas em um substrato inerte sem solo (Landell et al., 2012) e a nutrição é realizada por fertirrigação com molhamento do substrato e da superfície foliar. Portanto, acreditamos que o Si também pode ser inserido nos sistemas de fertilização para que as mudas recebam uma quantidade do elemento suficiente para induzir efeito benéfico após o transplantio. No entanto, como os teores foliares de Si e a sensibilidade ao déficit hídrico variam entre espécies, devido aos seus mecanismos fisiológicos e morfológicas específicos (Mauad et al., 2011), é pertinente avaliar se a quantidade de $\mathrm{Si}$ absorvido na fase de produção de mudas melhora os mecanismos de adaptação das plantas para diminuir os danos causados pelo déficit hídrico na fase posterior ao transplantio no campo, em MPB advinda tanto da cana-de-açúcar convencional quanto da cana-energia.

Por essa razão, o GENPLANT tem desenvolvido experimentos com o objetivo de avaliar o efeito residual da aplicação de Si na fase de produção de MPB na mitigação dos danos causados pelo déficit hídrico após o transplantio em dois genótipos de canade-açúcar (cana-convencional e cana-energia). Para isso, durante a fase de produção das mudas foi realizado 15 aplicações de Si via fertirrigação, com intervalos de 4 dias, na concentração de $2,5 \mathrm{mmol} \mathrm{L}^{-1}$, utilizando a fonte silicato de sódio e potássio estabilizado com sorbitol. $\mathrm{O}$ déficit hídrico foi induzido após o transplantio das mudas, considerando $30 \%$ da capacidade de retenção de água no solo, conforme indicado por Teixeira et al. (2020b) como um déficit hídrico severo em MPB. Foi avaliado o efeito residual da aplicação de Si na mitigação dos danos causados pelo déficit hídrico aos 60 dias após o transplantio das mudas para o solo.

Nas plantas não fertilizadas com Si em déficit hídrico, o conteúdo de água no tecido foliar diminuiu quando comparado à condição hídrica adequada. A quantidade de água foi maior com o suprimento de $\mathrm{Si}$ via fertirrigação em relação ao controle (-Si), sendo igual ao tratamento sem déficit hídrico, em cana-de-açúcar convencional (Figura 3a) e em cana-energia (Figura 4a).

O efeito mitigador do Si no aumento do conteúdo de água nas folhas sob déficit hídrico pode ser atribuído a manutenção do volume de água no tecido foliar causado pela formação de uma barreira física à perda de água devido à deposição de cristais de sílica no tecido epidérmico (Pei et al., 2010). Isso, associado a maior proteção na atividade de proteínas, que contribuem para a absorção de água, como as aquaporinas (Vandeleur et al., 2009), proporciona menor estresse oxidativo, aumento na quantidade de água tanto pela facilidade de absorção quanto pela diminuição de perdas (Liu et al., 2014).

$\mathrm{Na}$ ausência de $\mathrm{Si}$, o déficit hídrico diminuiu o número de perfilhos. Mas a nutrição com Si antes do transplantio aumentou o número de perfilhos quando comparado ao controle (-Si) tanto na cana-de-açúcar convencional (Figura 3b) quanto na cana-energia (Figura 4b). Nas plantas que não receberam Si, a área foliar também diminuiu com o déficit hídrico. Por outro lado, com fornecimento de $\mathrm{Si}$, a área foliar foi maior em relação ao controle (-Si) e isso ocorreu tanto na cana-de-açúcar convencional (Figura 3c) quanto na cana-energia (Figura 4c). 
(a)

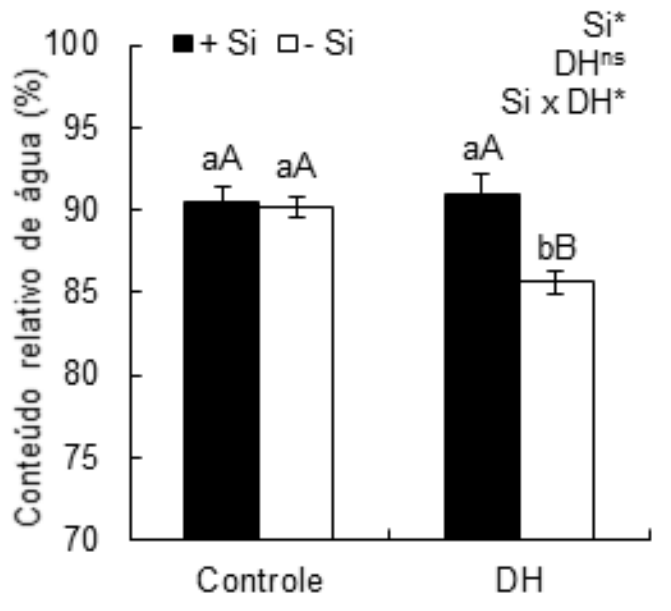

(c

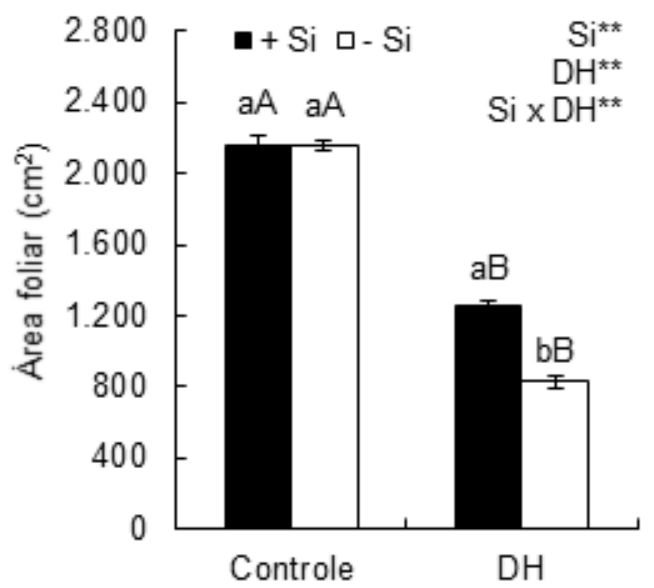

(b)

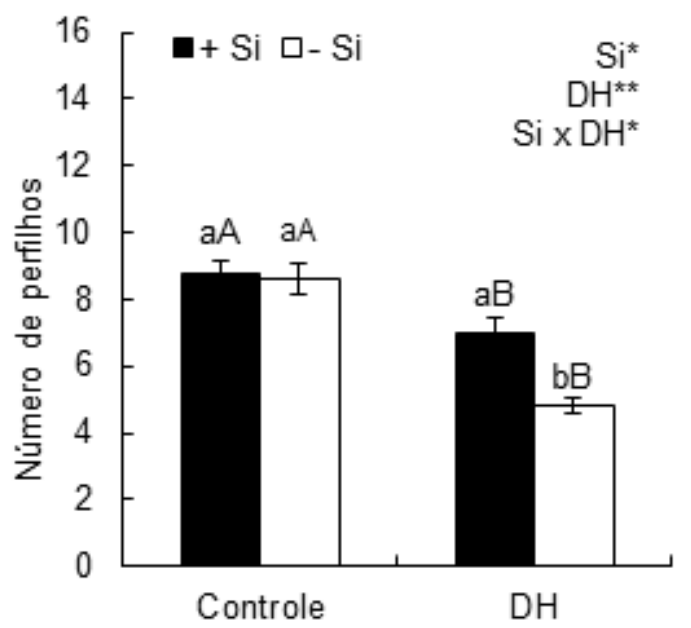

(d)

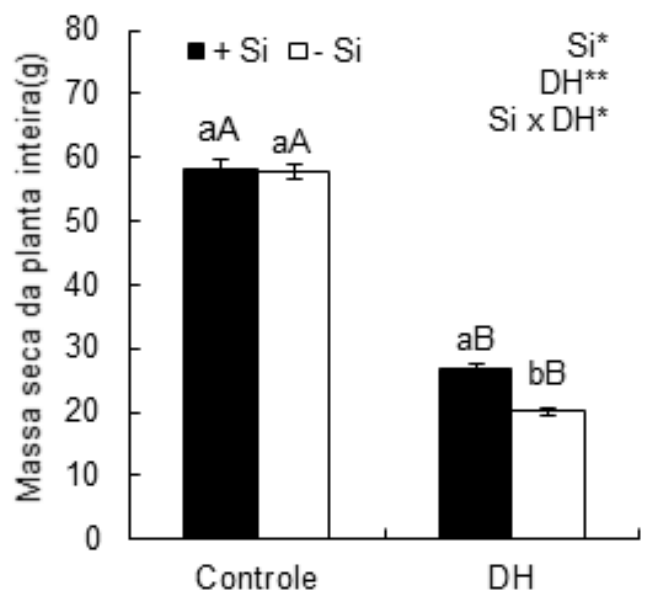

Figura 3 - Conteúdo relativo de água (a), número de perfilhos (b), área foliar (c) e massa seca da parte aérea (d) em mudas pré-brotadas de cana-de-açúcar convencional cultivada em $70 \%$ (controle) e 30\% (déficit hídrico - DH) da capacidade de retenção de água com (+Si) e sem (-Si) o fornecimento de silício (Si) via fertirrigação.

${ }^{* *} e^{*}$ : significativo a 1 e $5 \%$ de probabilidade, respectivamente e ns: não significativo pelo teste F. Letras minúsculas mostram diferenças em relação ao Si e letras maiúsculas em relação ao déficit hídrico. Barras representam o erro padrão da média, $\mathrm{n}=$ 6. Si x DH: interação. Fonte: Teixeira et al. (dados não publicados).

A produção de massa seca também foi afetada pelo déficit hídrico, sendo diminuída em até $65 \%$ em plantas da cana-de-açúcar convencional, que não receberam Si no estágio de produção de mudas, em relação às plantas cultivadas a $70 \%$ da capacidade de retenção de água no solo (Figura 3d). No entanto, a fertirrigação com Si foi eficiente para diminuir as perdas causadas pelo estresse, sobretudo, na produção de massa seca (Figura 3d). Dessa forma, fica evidente que fornecimento de Si via fertirrigação na fase de formação de MBP promove efeito residual que contribui para o aumento da tolerância ao déficit hídrico em espécies de cana-de-acúcar. Resultados semelhantes também foram encontrados por Camargo et al. (2019), mas utilizando doses maiores (600 kg ha-1) com aplicação de uma fonte insolúvel (silicato de cálcio e magnésio) no solo.

3.2.2. Silício mitiga os efeitos do déficit hídrico em diferentes fases do desenvolvimento da cana-de-açúcar

O déficit hídrico tem sido uma das principais limitações para diversas culturas no mundo inteiro e os seus efeitos estão em função da fase de desenvolvi- mento da planta. Os estágios iniciais de desenvolvimento da cana-planta são, geralmente, muito sensíveis ao déficit hídrico (Jain et al., 2015), sobretudo quando é utilizado o plantio de MPB porque o sistema radicular ainda não está completamente instalado e não há reservas de água e nutrientes proveniente do colmo como no sistema convencional. Uma outra fase de grande sensibilidade é o de rebrota da cana-soca, pois o corte também representa uma condição estressora para a planta (Sousa et al., 2015).

Os mecanismos morfofisiológicos da planta submetida ao déficit hídrico são modificados para garantir a sobrevivência, que dependerá da sua capacidade em se ajustar rapidamente à situação de estresse (Jain et al., 2015). Desse modo, se faz necessário a busca por estratégias para aumentar a tolerância ao déficit hídrico de culturas semi-perenes, como a cana-de-açúcar, em diferentes fases do desenvolvimento. Diante disso, o efeito do Si na atenuação dos danos causados pelo déficit hídrico tem sido abordado na literatura, sobretudo por modificar os mecanismos bioquímicos, fisiológicos e a proteção mecânica da parede celular das plantas, com reflexo no aumento da biomassa. 
(a)

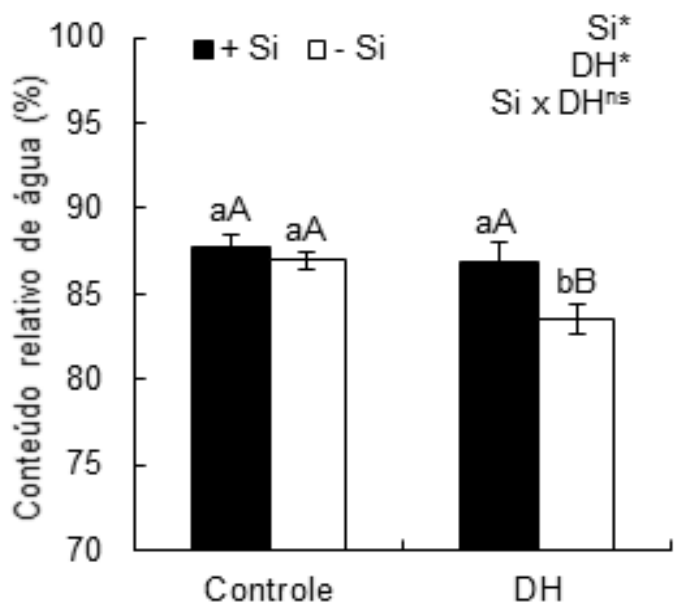

(c)

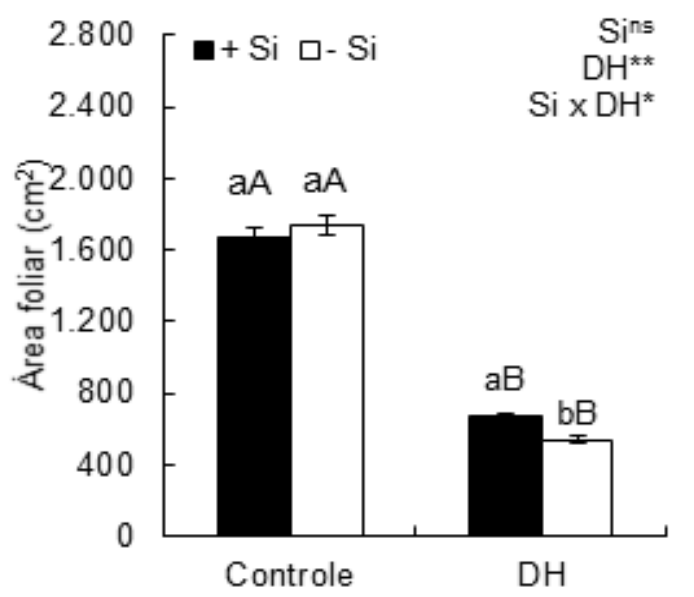

(b)

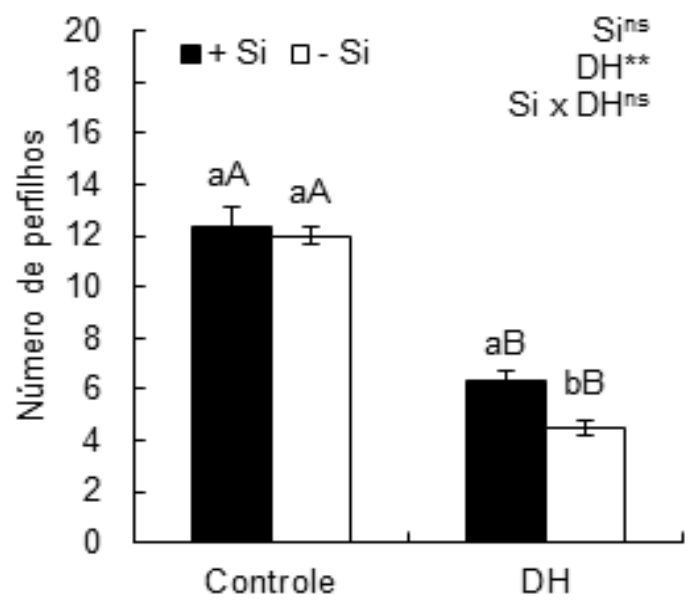

(d)

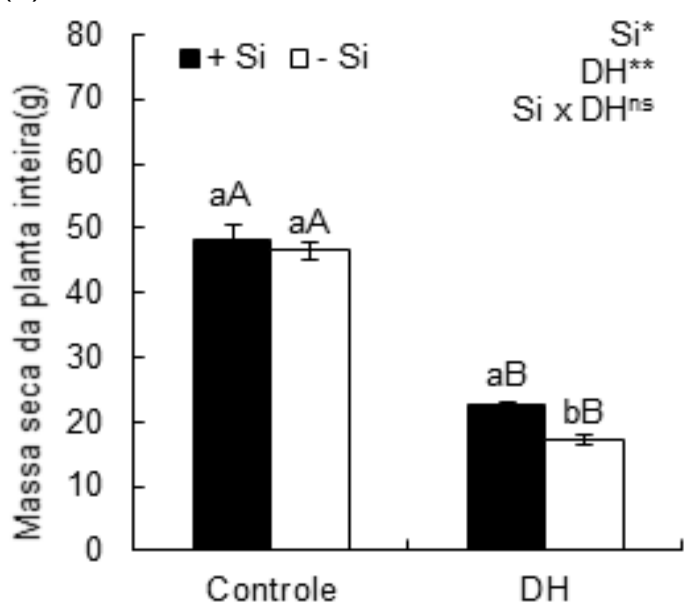

Figura 4 - Conteúdo relativo de água (a), número de perfilhos (b), área foliar (c) e massa seca da parte aérea (d) em mudas pré-brotadas de cana-energia cultivada em $70 \%$ (controle) e $30 \%$ (déficit hídrico - DH) da capacidade de retenção de água com (+Si) e sem (-Si) o fornecimento de silício (Si) via fertirrigação.

${ }^{* *} e^{*}$ : significativo a 1 e $5 \%$ de probabilidade, respectivamente; ns: não significativo pelo teste $\mathrm{F}$. Letras minúsculas mostram diferenças em relação ao Si e letras maiúsculas em relação ao déficit hídrico. Barras representam o erro padrão da média, $\mathrm{n}=6$. Si x DH: interação. Fonte: Teixeira et al. (dados não publicados).

Os efeitos benéficos do Si na mitigação dos danos causados pelo déficit hídrico na fase inicial de desenvolvimento das MPB após o transplantio foram relatados por Teixeira et al. (2020b). Os autores aplicaram Si via pulverização foliar e via radicular (solução nutritiva), na fase de produção das mudas, e avaliaram o efeito residual do Si na mitigação de níveis de déficits hídricos (50 e $30 \%$ da capacidade de retenção de água no solo - CRA), por um período de 30 dias após o transplantio. As mudas demonstraram sensibilidade ao déficit hídrico, sobretudo o severo (30\% de CRA), com diminuição do conteúdo de água e potencial hídrico foliar e reflexos no menor número de perfilhos e produção de massa seca.

No entanto, foi demonstrado que o fornecimento de Si via solução nutritiva foi eficiente para diminuir os efeitos do déficit hídrico nos primeiros 30 dias após o transplantio, sendo evidenciado pelo maior crescimento e produção de biomassa, porque aumentou a eficiência quântica do fotossistema II, preservou o conteúdo de pigmentos fotossintéticos, como clorofilas e carotenoides, manteve o potencial hídrico e o conteúdo de água foliar, diminuiu o extravasamento de eletrólitos celulares e o conteúdo de prolina livre e permitiu um maior crescimento e produção de biomassa (Teixeira et al., 2020b).

O período de rebrota da soqueira é outra fase do desenvolvimento da cultura onde os danos causados pelo déficit hídrico são muito expressivos. A baixa disponibilidade de água na fase de brotamento diminui a produtividade, principalmente nos anos em que 0 déficit hídrico é mais intenso (Souza et al., 2015). Em soqueira de cana-de-açúcar submetida a níveis de água e nitrogênio, observou-se que na fase inicial de desenvolvimento da soqueira houve incremento de $59 \%$ na área foliar entre a reposição hídrica de 0 e 100\% (Alves, 2014).

No entanto, os estudos que demonstram as alterações nos processos morfológicos e fisiológicos para a manutenção do crescimento de soqueira de cana-de-açúcar sob déficit hídrico ainda são incipientes e quando se avalia o efeito do Si na mitigação dos 
danos causados pelo déficit hídrico nessa fase de desenvolvimento não há nenhum relato. Dessa forma, o GENPLANT desenvolveu um experimento com a finalidade de avaliar se a aplicação de Si via fertirriga- ção em cana-soca é eficiente para aumentar as concentrações do elemento no tecido foliar, e se o Si absorvido é capaz de melhorar o desempenho das plantas sob déficit hídrico. a)

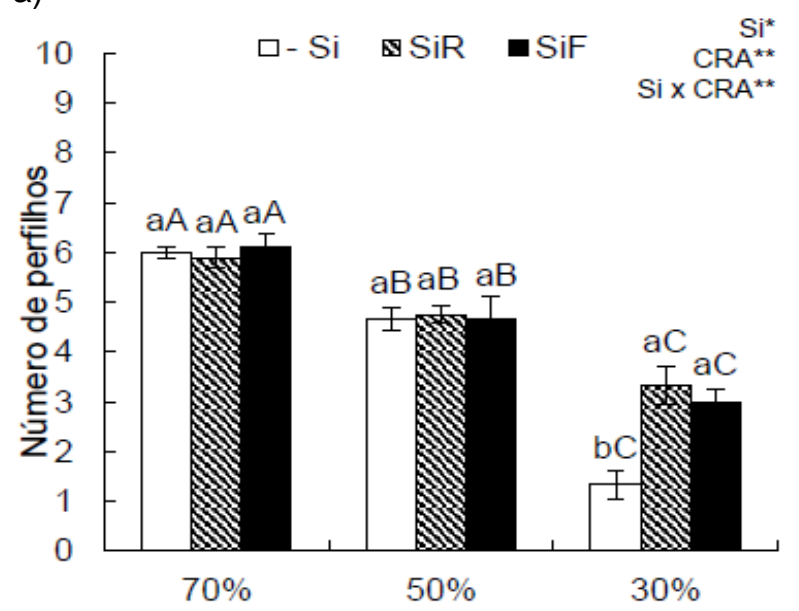

b)

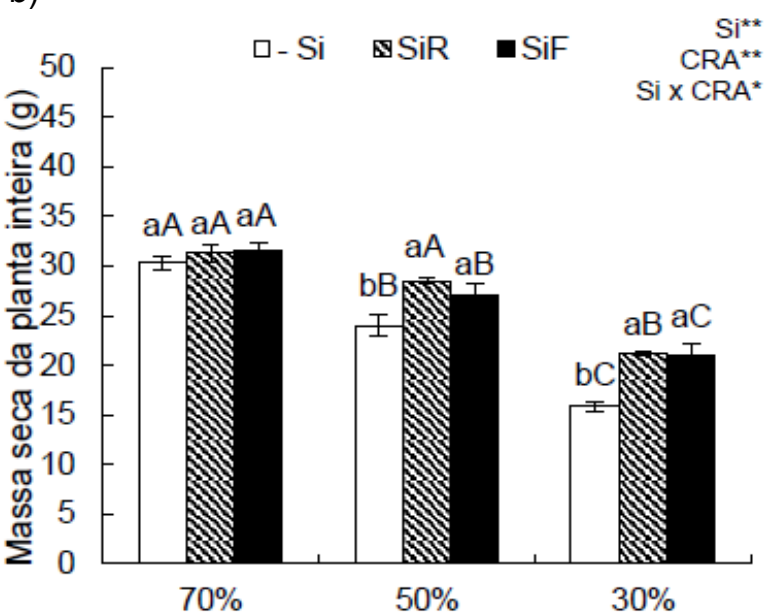

Figura 5 - Número de perfilhos (a) e massa seca da planta inteira (b) de mudas pré-brotadas de cana-de-açúcar sob níveis de capacidade de retenção de água no solo (CRA) (70, 50 e 30\%) e formas de fornecimento de Si (Sem Si: -Si; Si via solução nutritiva - radicular: SiR; Si via pulverização foliar: SiF).

${ }^{* *} \mathrm{e}^{*}$ : significativo a 1 e $5 \%$ de probabilidade, respectivamente; ns: não significativo pelo teste $\mathrm{F}$. Letras minúsculas demonstram diferenças em relação ao Si, e maiúsculas, em relação a CRA. As barras representam o erro padrão da média, $\mathrm{n}=6$. Si x CRA: interação. Fonte: Adaptado de Teixeira et al. (2020b).

Os resultados obtidos demonstram que existe grande sensibilidade das plantas ao déficit hídrico na fase de rebrota, e que a fertirrigação é uma técnica eficiente para o fornecimento de Si em cana-de-açúcar nesta fase. Foi possível observar que, independentemente da quantidade de água no solo, as plantas que receberam aplicação do elemento apresentaram maior acúmulo de Si (Figura 6a). Em razão disso, na presença de $\mathrm{Si}$, os danos causados pelo déficit hídrico foram diminuídos, como observado no aumento do número de perfilhos tanto em déficit hídrico como na condição controle (sem déficit) (Figura 6b).

Cabe ressaltar, que o efeito do $\mathrm{Si}$ em plantas sem déficit hídrico pode ser atribuído as condições de elevada temperatura na casa de vegetação, onde as plantas foram cultivadas, induzindo estresse térmico. A massa seca da planta inteira também foi influenciada pela restrição hídrica, sendo que a presença de $\mathrm{Si}$ contribuiu para o aumento da produção de massa seca, mesmo em plantas submetidas a condição de déficit hídrico (Figura 6c)

O uso da fertirrigação em áreas de cultivo de cana-de-açúcar é uma estratégia promissora porque permite aumentar a eficiência das fertilizações pelo uso de fontes solúveis e estáveis, como os silicatos estabilizados com polióis, em substituição das fontes de silicato de cálcio e silicato de magnésio, que exigem incorporação ao solo devido à baixa solubilidade em água, pois são fontes provenientes de rochas ou resíduos industriais (Keeping, 2017). A técnica ganha maior destaque para o fornecimento de Si na fase de rebrota da soqueira, pois através da fertirrigação é possível aplicar o elemento em quantidades requeridas pela cultura de maneira mais eficiente e sem necessidade de incorporação, o que poderia danificar o sistema radicular das plantas (Quintana et al., 2012).

Os estudos realizados demonstram a importância de se obter respostas sobre o efeito do Si como mitigador dos efeitos do déficit hídrico em diferentes fases do desenvolvimento da cultura da cana-de-açúcar, como na fase inicial de desenvolvimento após o transplantio de MPB, e na fase de rebrota da soqueira, pois são fases de grande sensibilidade ao déficit hídrico e decisivas para a formação da produtividade das áreas de cultivo. Dessa forma, apresentamos resultados de trabalhos que podem contribuir para a solução de problemas que ainda limitam a produção, para que cada vez mais se possa aumentar a longevidade do canavial e elevar as produtividades atuais.

\subsubsection{Silício mitiga os efeitos do déficit hídrico} em cana-de-açúcar cultivada em diferentes solos

No Brasil, a cana-de-açúcar é cultivada em condições edofaclimáticas distintas, o que permite sua exploração em praticamente todo o território nacional. Logo, o cultivo é feito em regiões com variadas classes de solos, que se diferenciam, sobretudo, na capacidade de retenção de água. $\mathrm{O}$ estresse por falta de água na cultura da cana-de-açúcar afeta o desempenho fisiológico, levando a diminuição no desenvolvimento do sistema radicular, como menor comprimento e volume de raízes; bem como da parte aérea, com diminuição do perfilhamento e diâmetro dos colmos (Jangpromma et al., 2012). 
(a)

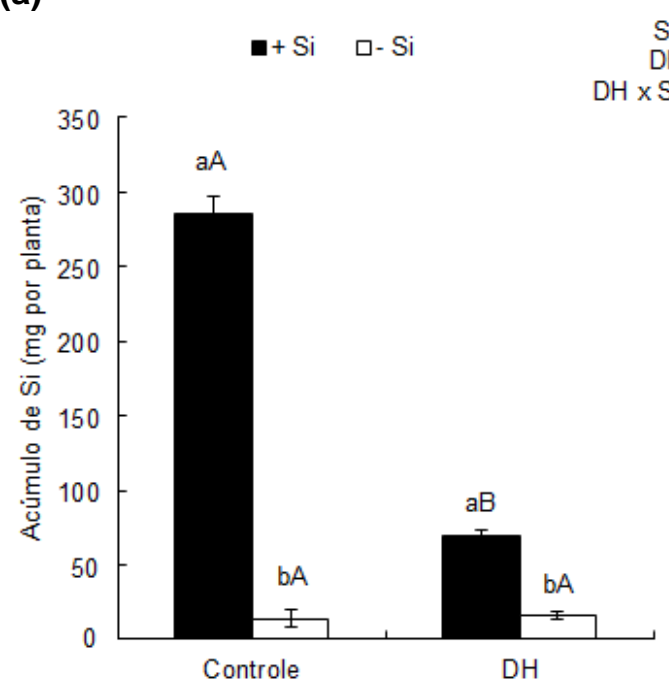

(b)

$\mathrm{i}^{* *}$

$\mathrm{DH}^{* *}$
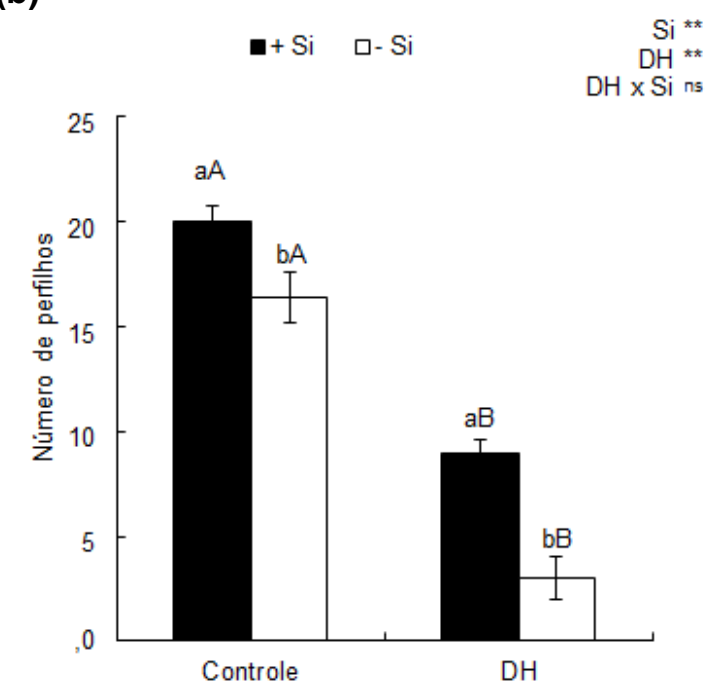

(c)

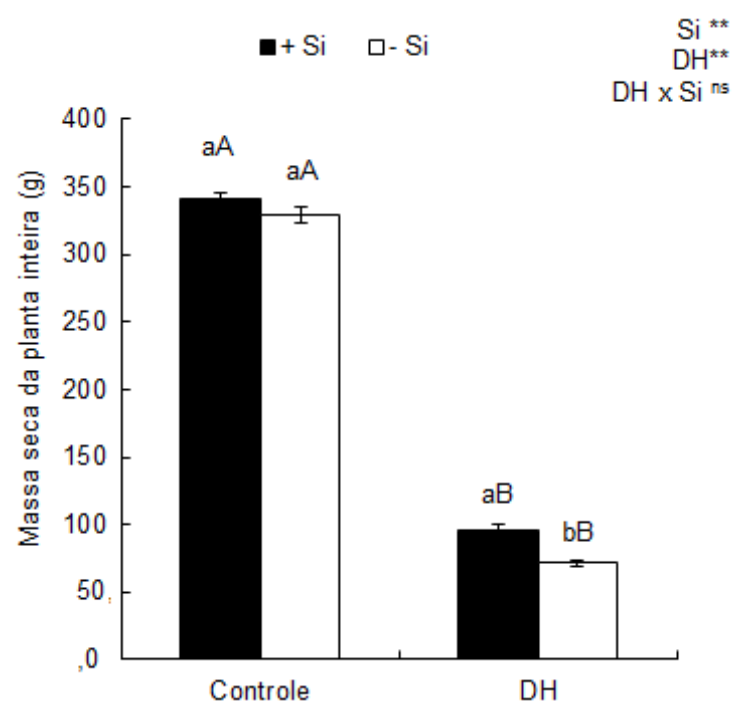

Figura 6 - Acúmulo de silício (Si) (a), número de perfilhos (b), massa seca da planta inteira (c) de soqueira de plantas de cana-energia cultivada em $70 \%$ (controle) e 30\% (déficit hídrico - DH) da capacidade de retenção de água com $(+\mathrm{Si})$ e sem $(-\mathrm{Si})$ o fornecimento de Si via fertirrigação.

${ }^{* *} e^{*}$ : significativo a 1 e $5 \%$ de probabilidade, respectivamente; " ns: não significativo pelo teste F. Letras minúsculas mostram diferenças em relação ao Si e letras maiúsculas em relação ao déficit hídrico. Barras representam o erro padrão da média, $\mathrm{n}=6$. Si x DH: interação. Fonte: Oliveira Filho et al. (dados não publicados).

Estudos indicam que o Si pode atenuar os estresses de plantas em situação de seca, pois atua na proteção física e química dos vegetais, favorecendo o desempenho fisiológico, melhorando o sistema antioxidante, que resulta em maior produção de biomassa (Chen et al., 2018; Camargo et al., 2017). Em solos argilosos, o teor de Si pode variar de $200 \mathrm{a} 300 \mathrm{~g} \mathrm{~kg}^{-1} \mathrm{e}$ em solos arenosos, o teor médio é de $450 \mathrm{~g} \mathrm{~kg}^{-1}$ (Kovda, 1973). Entretanto, grande parte desse elemento presente no solo está na forma inerte, não disponível em solução, o que limita a absorção pelas plantas, que só ocorre, quando o Si está na forma de ácido monossílicico $\left(\mathrm{H}_{4} \mathrm{SiO}_{4}\right)$, geralmente presente em concentrações de 1 a 2,0 mM (Epstein, 1994).

A baixa disponibilidade de Si assimilável para as plantas é maior em regiões de clima tropical, onde os solos sofrem com constante dessilicação devido à lixiviação, pela elevada acidez e baixos valores de saturação por bases (Keeping, 2017), características comuns em solos das classes Argissolos, Latossolos e Neossolos, que são solos altamente intemperizados e apresentam baixos teores de Si (Savant et al., 1999; Meyer \& Keeping, 2001). Isso se agrava porque os solos com essas características também apresentam baixas concentrações de cálcio, magnésio e potássio disponíveis para as plantas, já que foram submetidos a intempéries e lixiviação intensas, como é comum em regiões quentes e úmidas (Tubana et al., 2016).

Além das características naturais do solo, a deficiência de Si pode se intensificar em áreas com plantios de plantas acumuladoras do elemento, como a cana-de-açúcar, que chega a remover até $700 \mathrm{~kg} \mathrm{ha}^{-1}$ 
ao ano (Meena et al., 2014; Keeping, 2017). Por essa razão, tem sido observado diminuição no desempenho produtivo de culturas em cultivos em todo o mundo, consequência do esgotamento do Si disponível no solo, causado pela falta de reposição do elemento por muitos cultivos consecutivos (Yan et al., 2018). Logo, o fornecimento de $\mathrm{Si}$ via fertilizantes é importante para manutenção da produtividade dos sistemas de produção agrícola.

A cana-de-açúcar é uma das culturas que responde positivamente ao suprimento de $\mathrm{Si}$, sobretudo, quando cultivada em solos deficientes nesse elemento (Keeping, 2017). Em estudos realizados em Neossolos Quartzarênicos, resultados benéficos foram observados por Camargo et al. (2017), que ao submeterem a cultura ao déficit hídrico em diferentes estádios de desenvolvimento da cana-planta, perceberam que houve aumento da produtividade de colmos e da produção de massa seca e de açúcar após as plantas receberem $600 \mathrm{~kg} \mathrm{ha}^{-1}$ de Si via solo na forma de silicato de cálcio e magnésio.

No entanto, ainda são utilizadas grandes quantidades de Si com o uso de fontes insolúveis que exigem incorporação ao solo. Dessa forma, busca-se aumentar a eficiência das fertilizações com Si usandose fontes com maior estabilidade da forma monomérica, como os silicatos estabilizados que podem ser uma excelente alternativa, pois favorecem a maior disponibilidade e absorção do elemento pelas plantas. Em adição, o fornecimento de Si via água de irrigação pode melhorar a disponibilização do elemento e contribuir para a manutenção de lavouras visando garantir a sustentabilidade de sua produção.

Desse modo, o GENPLANT em parceria com - GPIMA desenvolveu experimentos com cana-de-açúcar originada de MPB, com o objetivo de avaliar o efeito do $\mathrm{Si}$ aplicado via fertirrigação nas plantas cultivadas sob déficit hídrico em diferentes solos. Foi aplicado 1,8 mmol L-1 de Si via fertirrigação em MPB de cana-de-açúcar sob 70 e $35 \%$ da capacidade de retenção de água no solo (CRA) cultivadas em vasos preenchidos com amostras de Neossolo Quartzarênico e de Latossolo Vermelho. A fonte de Si utilizada foi o silicato de sódio e potássio estabilizado com sorbitol e foram realizadas aplicações de $\mathrm{Si}$ a cada dois dias durante 5 meses de cultivo das plantas. Ao final, foram avaliados parâmetros de crescimento como área foliar, diâmetro do colmo, número de perfilhos, massa seca da parte aérea e índice de extravasamento de eletrólitos.

Plantas de cana-de-açúcar cultivadas em amostras de Neossolo Quartzarênico sob déficit hídrico (35\% da CRA) apresentaram menor área foliar, diâmetro do colmo, número de perfilhos, massa seca da parte aérea e maior índice de extravasamento de eletrólitos quando comparadas as plantas sob condições hídricas desejáveis (70\% CRA), indicando a ocorrência do estresse. Por outro lado, o fornecimento de Si via fertirrigação às plantas de cana-de-açúcar em déficit hídrico proporcionou maior área foliar, diâmetro do colmo, número de perfilhos, massa seca da parte aérea e menor índice de extravasamento de eletrólitos, quando comparado às plantas não tratadas com elemento (Figura 7a-e).

Assim como no experimento realizado em Neossolo Quartzarênico, as plantas de cana-de-açúcar cultivadas em Latossolo Vermelho sob déficit hídrico (35\% da CRA) apresentaram menor área foliar, diâmetro do colmo, número de perfilhos, massa seca da parte aérea e maior índice de extravasamento de eletrólitos, comparadas as plantas que não foram submetidas a restrição hídrica ( $70 \%$ da CRA). Entretanto, com o Si aplicado via fertirrigação as plantas de cana-de-açúcar na condição de déficit hídrico aumentaram a área foliar, o diâmetro do colmo, o número de perfilhos, a massa seca da parte aérea e diminuiu o índice de extravasamento de eletrólitos (Figura 8a-e). As plantas cultivadas em $70 \%$ da CRA diferiram quanto ao fornecimento de $\mathrm{Si}$ apenas quanto ao número de perfílhos (Figura 8c).

As mudas de cana-de-açúcar cultivadas tanto em Neossolo quanto em Latossolo, quando submetidas ao déficit hídrico na ausência de $\mathrm{Si}$, apresentaram maior estresse e menor crescimento, culminando em prejuízos na produção de massa seca. Respostas similares também foram observadas por outros autores, mas em cana-de-açúcar obtida pelo sistema convencional, como Jangpromma et al. (2012) que ao avaliarem o crescimento de dez genótipos de cana-de-açúcar submetidas ao déficit hídrico, verificaram diminuição no diâmetro do caule e na produção de biomassa. Outros autores como Machado et al. (2009), que avaliando dois genótipos de cana-de-açúcar submetidos ao déficit hídrico em diferentes fases fenológicas, observaram menor altura das plantas e número e comprimento de entrenós, que resultou em menor acúmulo de matéria seca no colmo.

O fornecimento de Si via fertirrigação aliviou os estresses ocasionados pelo déficit hídrico, observado pelo menor índice de extravasamento de eletrólitos (Figura 7e e 8e) que proporcionou maior área foliar, melhor desenvolvimento de colmo, maior perfilhamento e a produção de massa seca (Figuras 7 e 8). O Si diminui os efeitos do déficit hídrico porque ao ser absorvido pelas plantas, é transportado até as folhas, acumulando-se na parede celular e nos espaços intercelulares na forma de sílica amorfa, o que resulta no fortalecimento da parede vegetal e melhor desenvolvimento das plantas (Epstein, 1999; Ma, 2004; Ma \& Yamaji, 2006). Esse processo se torna ainda mais intenso em plantas monocotiledôneas, a exemplo da cana-de-açúcar, que acumulam grandes quantidades do elemento, sendo altamente responsiva ao seu fornecimento (Meena et al., 2014; Keeping, 2017).

Além do fortalecimento físico, o alívio dos estresses causados pelo déficit hídrico em plantas tratadas com Si também pode ser justificado pelo ele- 
mento contribuir no aperfeiçoamento do transporte de água na raiz, através do aumento da atividade das aquaporinas, que são proteínas especializadas na absorção de água pelas plantas que tem a expressão de seus genes (PIPs) estimulada pelo Si (Chen et al., 2016). As respostas obtidas nesses experimentos demonstram que a cana-de-açúcar é uma cultura que requer o suprimento de grande quantidade de $\mathrm{Si}$ ao longo de seu cultivo e quando cultivadas em solos das classes dos Neossolos e dos Latossolos, que são altamente intemperizadas (Savant et al., 1999; Meyer e Keeping 2001), respondem de maneira positiva a fertilização com Si.
- $-\mathbf{S i}$
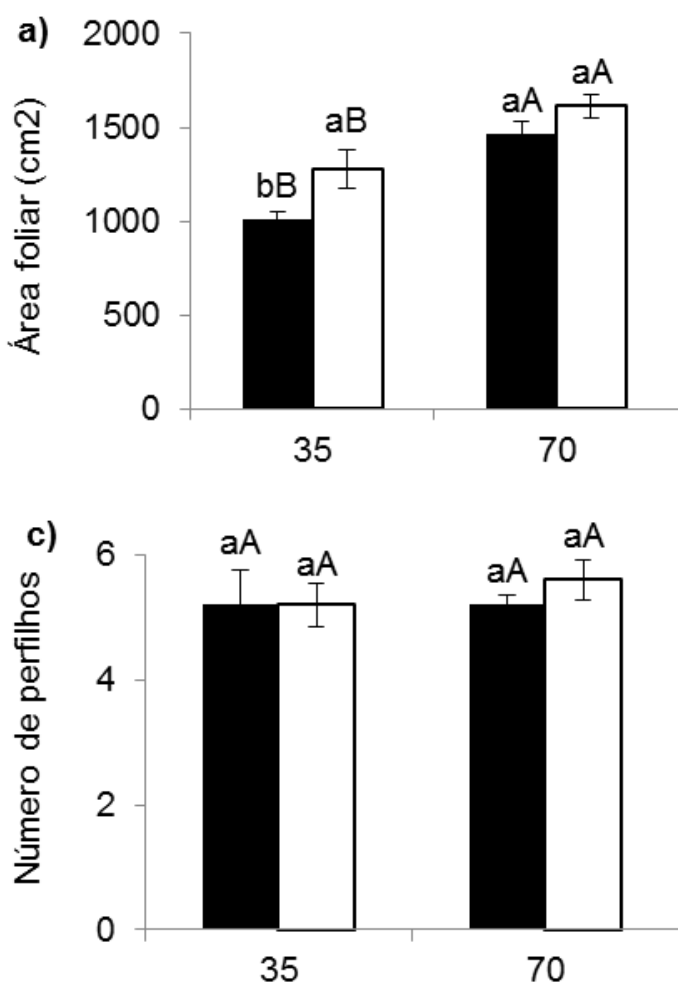

e) 40

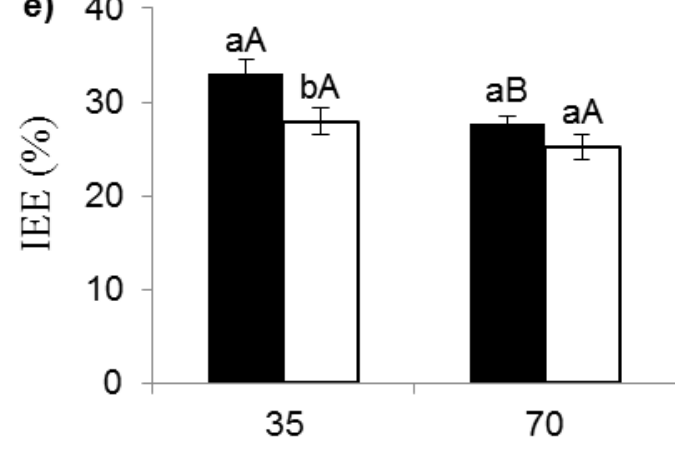

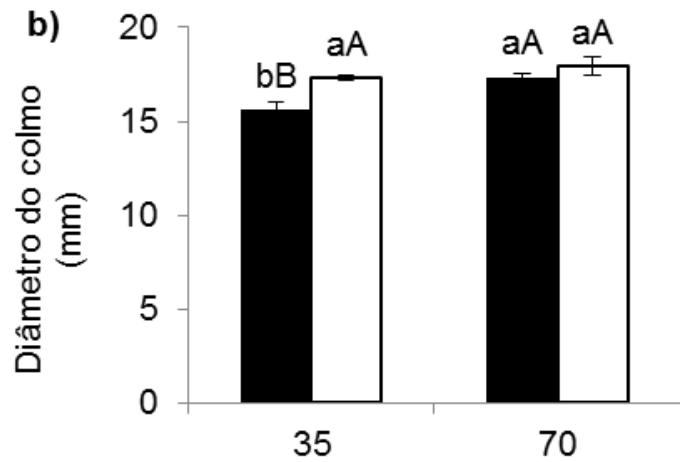

d)
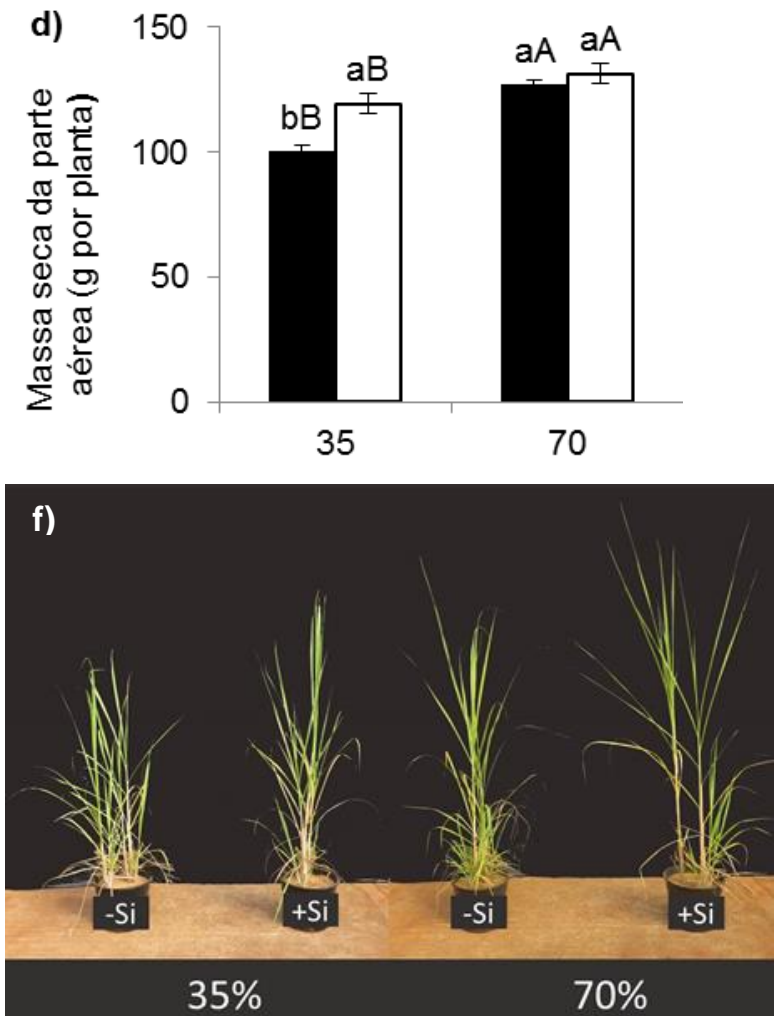

Figura 7 - Área foliar (a), diâmetro do colmo (b), número de perfilhos (c), massa seca da parte aérea (d), índice de extravasamento de eletrólitos (e) e comparação do desenvolvimento da parte aérea de plantas de cana-de-açúcar cultivadas em Neossolo Quartzarênico sob dois níveis de capacidade de retenção de água no solo (CRA) (35 e 70\%) e fornecimento de silício (Si): ausência de Si (-Si) e presença de (+Si) (f).

Letras minúsculas diferentes indicam diferenças significativas na mesma CRA e letras maiúsculas diferentes indicam diferenças significativas entre a disponibilidade de $\mathrm{Si}$, pelo teste de Tukey a $5 \%$ de probabilidade. Fonte: Sarah et al. (dados não publicados). 
$-\mathbf{S i}$
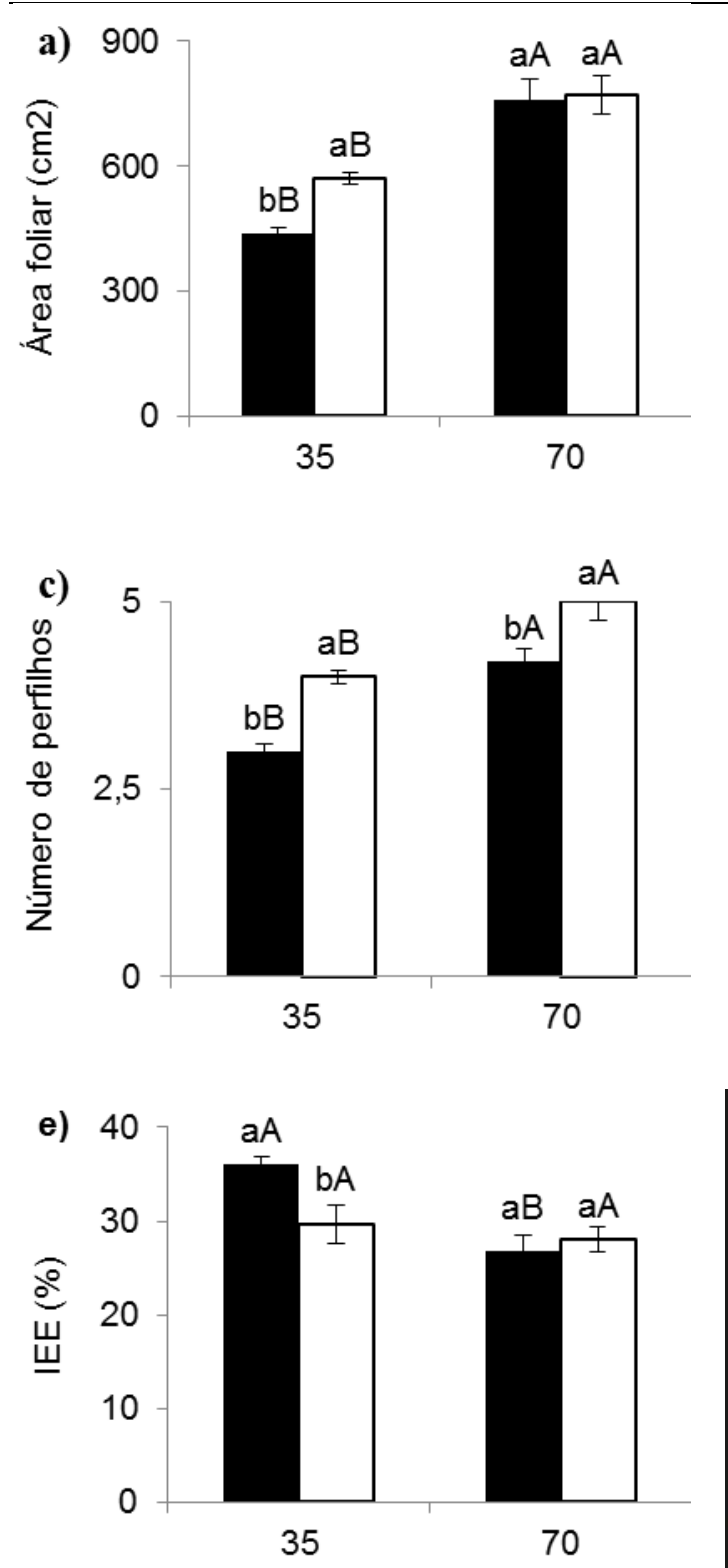

$\square+\mathbf{S i}$
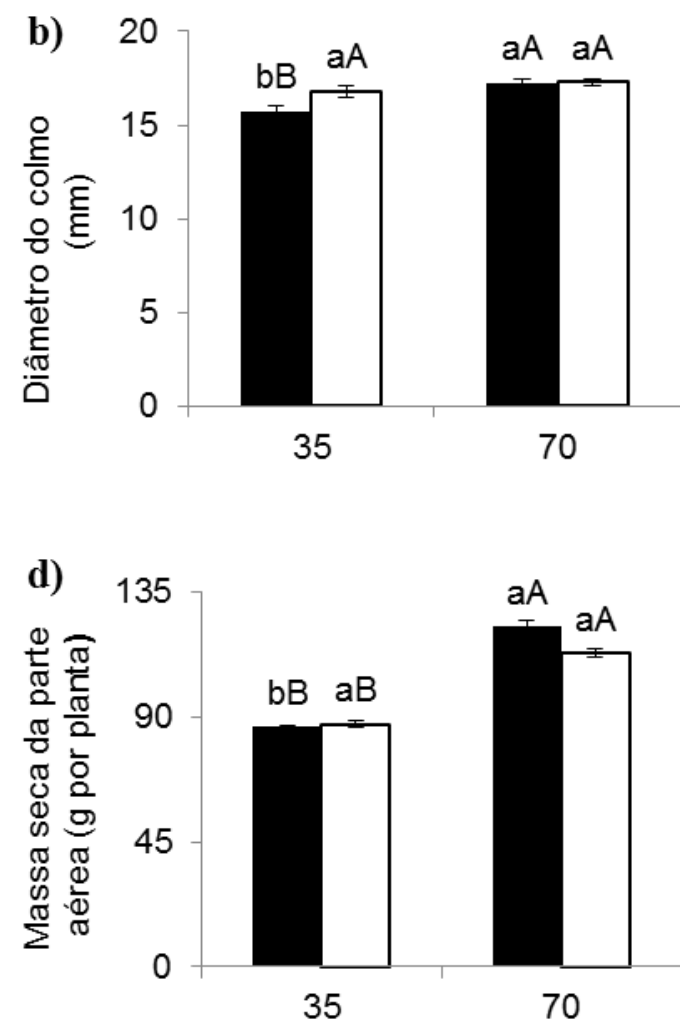

Figura 8 - Área foliar (a), diâmetro do colmo (b), número de perfilhos (c), massa seca da parte aérea (d), índice de extravasamento de eletrólitos (IEE) (e) e comparação do desenvolvimento da parte aérea de plantas de cana-de-açúcar cultivadas em Latossolo vermelho sob dois níveis de capacidade de retenção de água no solo (CRA) (35 e 70\%) e fornecimento de silício (Si): ausência de Si (-Si), e presença de (+Si) (f).

Letras minúsculas diferentes indicam diferenças significativas na mesma CRA e letras maiúsculas diferentes indicam diferenças significativas entre a disponibilidade de $\mathrm{Si}$, pelo teste de Tukey a $5 \%$ de probabilidade. Fonte: Sarah et al. (dados não publicados).

Resultados benéficos com uso de Si também foram observados por Teixeira et al. (2020b), que ao fornecerem Si às MPB cultivadas sob déficit hídrico em amostras de Latossolo, concluíram que houve menor estresse, pois o elemento diminuiu o extravasamento de eletrólitos e favoreceu o acúmulo de biomassa. Autores como Camargo et al. (2019), que avaliando efeitos da adubação silicatada e o déficit hídrico imposto durante duas safras de cana-de-açúcar cultivadas em amostras de um Neossolo Quartzarênico típico, também verificaram que o elemento benéfico proporcionou maior desempenho fisiológico que resultou em aumento na massa seca. Dessa forma, fica evidente que o Si pode ser considerado uma alternativa para a diminuição dos estresses ocasionados por déficit hídrico em plantas de cana-de-açúcar cultivadas em diferentes tipos de solo, tendo seu efeito potencializado quando o ambiente sofre com deficiência do elemento.

Diante disso, os mecanismos básicos de atuação do Si aplicado via fertirrigação na mitigação dos 
danos causados pelo déficit hídrico em MPB de canade-açúcar demonstrados nesta revisão são apresentadas graficamente (Figura 9), onde plantas de recebem a aplicação do elemento, aumentam a proteção física da parede celular, pois se trata de uma cultura da família Poaceae, classificados como acumuladora do elemento. Nota-se que o conteúdo de água nas células é preservado mesmo com a restrição hídrica, o que diminui o estresse da planta e resulta em maior crescimento observado pela maior altura, área foliar, diâmetro do colmo, número de perfilhos e, conse- quentemente, maior acúmulo de massa seca.

Espera-se que as mudas da cana-de-açúcar com maior tolerância aos estresses possam garantir maior vigor durante crescimento inicial, conforme relatado pelas pesquisas apresentadas. Esses efeitos do uso do Si em MPB podem diminuir as falhas na cana-planta e garantir culturas mais homogêneas refletindo, possivelmente, em maior produtividade da cana-planta e até das soqueiras subsequentes, mas é necessário avançar nas pesquisas para estimar com precisão os benefícios deste elemento durante todo ciclo da cultura.

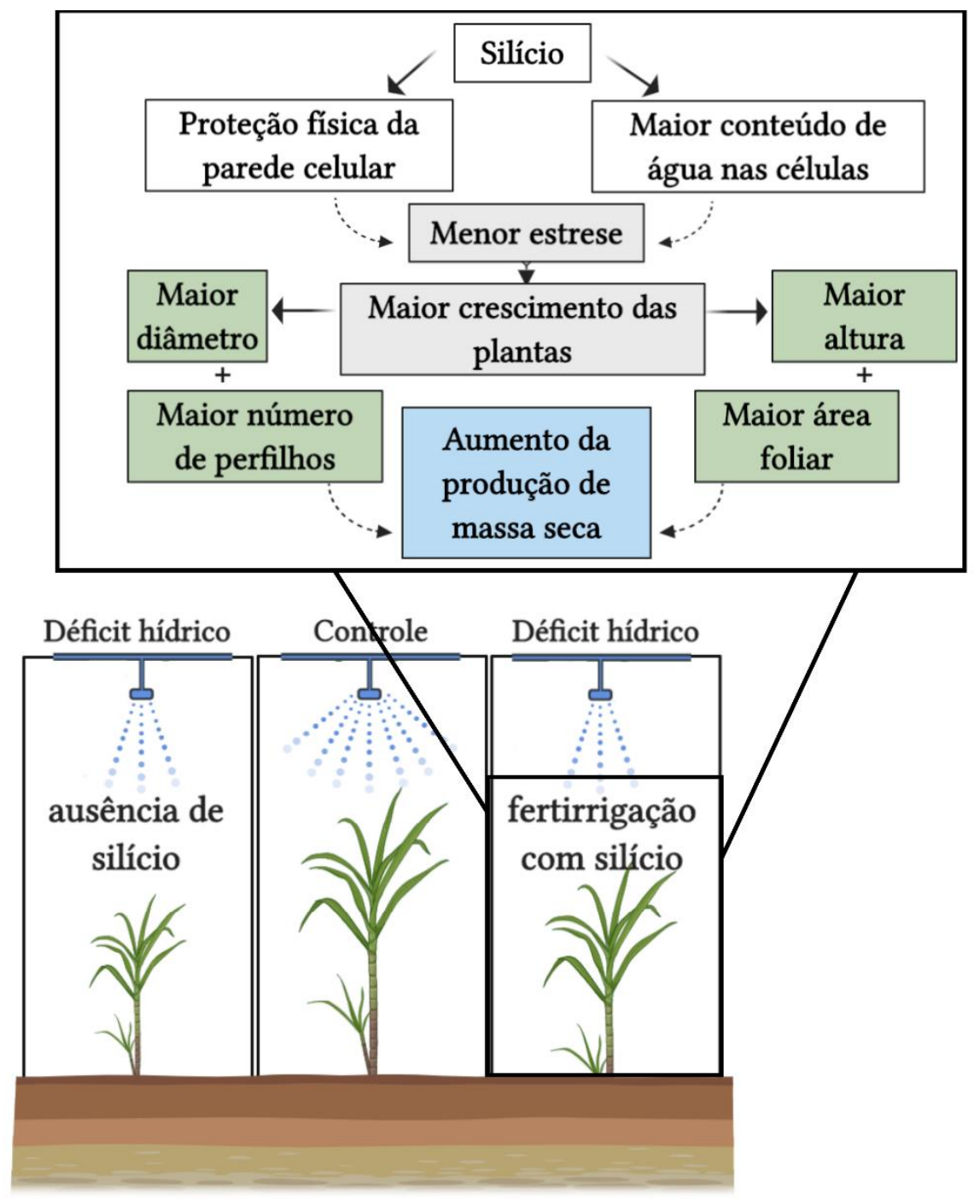

Figura 9 - Esquema indicando o efeito da aplicação de silício via fertirrigação em mudas pré-brotadas de cana-de-açúcar. Fonte: Elaborado pelos autores.

\section{Considerações finais e perspectivas futuras}

O fornecimento de silício em mudas pré-brotadas de cana-de-açúcar deve ser considerado uma nova estratégia de manejo nos sistemas de produção porque pode aumentar a tolerância aos danos causados pela deficiência nutricional, sobretudo, a causada por baixos teores de manganês no solo, e pelo déficit hídrico em diferentes genótipos de cana-de-açúcar e em fases distintas do desenvolvimento da cultura, cultivada em diferentes tipos de solos.

A perspectiva é que o uso do silício possa também beneficiar novos sistemas como semente artificial de cana-de-açúcar constituída por cápsulas contendo propágulos vegetativos e espera-se que novas pesquisas sejam realizadas com esse elemento benéfico. 


\section{Referências}

Alves BA (2014) Desempenho agronômico e produtividade de soqueira de cana-de-açúcar submetida a diferentes níveis de água e nitrogênio. Instituto Federal de Educação, Ciência e Tecnologia Goiano (Dissertação em Ciências Agrárias - Agronomia).

Basnayake J, Jackson PA, Inman-Bamber NG, Lakshmanan P (2012) Sugarcane for water-limited environments. Genetic variation in cane yield and sugar content in response to water stress. Journal of Experimental Botany 63: 6023-6033. https://doi.org/10.1093/jxb/ers251

Bezerra BKL, Lima GPP, dos Reis AR, Silva M de A, de Camargo MS (2019) Physiological and biochemical impacts of silicon against water deficit in sugarcane. Acta Physiologiae Plantarum 41: 189. https://doi.org/10.1007/s11738-019-2980-0

Bityutskii N, Pavlovic J, Yakkonen K, Maksimović V, Nikolic M (2014) Contrasting effect of silicon on iron, zinc and manganese status and accumulation of metalmobilizing compounds in micronutrient-deficient cucumber. Plant Physiology and Biochemistry 74:205221.doi: 10.1016/j.plaphy.2013.11.015

Bokhtiar SM, Huang HR, Li YR, Dalvi VA (2012) Effects of silicon on yield contributing parameters and its accumulation in abaxial epidermis of sugarcane leaf blades using energy dispersive x-ray analysis. Journal of Plant Nutrition 35: 1255-1275.

Burnell JN (1988) The biochemistry of manganese in plants. In: Graham RD, Hannam RJ, Uren NC. (Ed). Manganese in soils and plants. Dordrecht: Kluwer Academic Publishers, 125-137. doi: 10.1007/978-94009-2817-6_10

Camargo MS, Bezerra BKL, Holanda LA, Oliveira AL, Vitti AC, Silva MA (2019) Silicon Fertilization Improves Physiological Responses in Sugarcane Cultivars Grown Under Water Deficit. Journal of Soil Science and Plant Nutrition 19: 81-91. doi: 10.1007/s42729-019-0012-1

Camargo MS, Bezerra BKL, Vitti AC, Silva MA, Oliveira $A L$ (2017) Silicon fertilization reduces the deleterious effects of water deficit in sugarcane. Journal of soil Science and Plant Nutrition 17: 99-111.

Cao B, Ma Q, Zhao Q, Wang L, Xu K (2015) Effects of silicon on absorbed light allocation, antioxidant enzymes and ultrastructure of chloroplasts in tomato leaves under simulated drought stress. Scientia Horticulturae 194: 53-62. doi: 10.1016/j.scienta.2015.07.037

Carvalho-Netto OV, Bressiani JA, Soriano HL, Fiori CS, Santos JM, Barbosa GVS, Xavier MA, Landell MGA, Pereira GAG (2014) The potential of the energy cane as the main biomass crop for the cellulosic industry. Chemical and Biological Technologies in Agriculture 1:1-20. doi: 10.1186/s40538-014-0020-2
Chen D, Cao B, Wang S, Liu P, Deng X, Yin L, Zhang S (2016) Silicon moderated the K deficiency by improving the plant-water status in sorghum. Scientific reports 6 .

Chen D, Wang S, Yin L, Deng X (2018) How Does Silicon Mediate Plant Water Uptake and Loss Under Water Deficiency? Frontiers in Plant Science 9: 281.

Ducic T, Polle A (2005) Transport and detoxification of manganese and copper in plants. Brazilian Journal of Plant Physiology 17: 103-112.

Epstein E (1994) The anomaly of silicon in plant biology. Proceedings of the National Academy of Sciences of the United States of America91:1-17.

Epstein E (1999) Silicon. Annual review of plant biology 50: 641-664.

Felisberto G (2018) Silício na mitigação de estresse por deficiência de zinco em plantas de arroz e soja. Unesp (Tese de doutorado em Agronomia).

Gírio LAS, Dias FLF, Reis VM, Urquiaga S, Schultz N, Bolonhezi D, Mutton MA (2015) Bactérias promotoras de crescimento e adubação nitrogenada no crescimento inicial de cana-de-açúcar proveniente de mudas pré-brotadas. Pesquisa Agropecuária Brasileira 50: 3343.

Gong $\mathrm{H}$, Chen $\mathrm{K}$ (2012) The regulatory role of silicon on water relations, photosynthetic gas exchange, and carboxylation activities of wheat leaves in field drought conditions. Acta Physiologiae Plantarum 34: 15891594. doi: 10.1007/s11738-012-0954-6

Gong H, Zhu X, Chen K, Wang S, Zhang C (2005) Silicon alleviates oxidative damage of wheat plants in pots under drought. Plant Science 169: 313-321. https://doi.org/10.1016/j.plantsci.2005.02.023

Gonzalo MJ, Lucena JJ, Hernández-Apaolaza L (2013) Effect of silicon addition on soybean (Glycine max) and cucumber (Cucumis sativus) plants grown under iron deficiency. Plant Physiology and Biochemistry 70: 455461. doi: 10.1016/j.plaphy.2013.06.007

Greger M, Landberg T, Vaculík M (2018). Silicon influences soil availability and accumulation of mineral nutrients in various plant species. Plants 7(2):41. doi:10.3390/plants7020041

Hoagland DR, Arnon D (1950) The water culture method for growing plant without soil. Agricutural Experiment Station 347: 1-32.

Jain R, Chandra A, Venugopalan VK, Solomon S (2015) Physiological changes and expression of sod and p5cs genes in response to water deficit in sugarcane. Sugar Tech 17: 276-282. doi: 10.1007/s12355-014-0317-2 
Jangpromma $N$, Thammasirirak $S$, Jaisil $P$, Songsri $P$ (2012) Effects of drought and recovery from drought stress on above ground and root growth, and water use efficiency in sugarcane ('Saccharum officinarum' L.). Australian Journal of Crop Science 6(8): 1298.

Keeping MG (2017) Uptake of silicon by sugarcane from applied sources may not reflect plant-available soil silicon and total silicon content of sources. Frontiers in Plant Science 8: 1-14. doi: 10.3389/fpls.2017.00760.

Kovda VA (1973) The bases of learning about soils, v.2. Nauka, Moscow

Landell MG, Campana M, Figueiredo P, Xavier M, Anjos I, Dinardo-Miranda L, Scarpari M, Garcia J, Bidóia M, Silva D, Mendonça J, Kanthack R, Campos M, Brancalião S, Petri R, Miguel P (2012) Sistema de multiplicação de cana-de-açúcar com uso de mudas pré-brotadas (MPB), oriundas de gemas individualizadas (n‥ 109), Campinas: Documentos IAC.

Liang Y, Sun W, Zhu YG, Christie P (2007) Mecanismos de alívio mediado por silício de estresses abióticos em plantas superiores: uma revisão. Environmental $\begin{array}{llll}\text { Pollution } & \text { 147: }\end{array}$ 10.1016/j.envpol.2006.06.008

Lidon FC, Barreiro M, Ramalho J (2004) Manganese accumulation in rice: implications for photosynthetic functioning. Journal of Plant Physiology 161: 1235-1244. doi: 10.1016 / j.jplph.2004.02.003

Liu P, Yin L, Deng X, Wang S, Tanaka K, Zhang S (2014) Aquaporin-mediated increase in root hydraulic conductance is involved in silicon-induced improved root water uptake under osmotic stress in Sorghum bicolor L. Journal of Experimental Botany 65: 4747-4756. https://doi.org/10.1093/jxb/eru220

Lux A, Luxova M, Hattori T, Inanaga S, Sugimoto $Y$ (2002) Silicification in sorghum (Sorghum bicolor) cultivars with different drought tolerance. Physiologia Plantarum 115: 87-92.

Ma JF (2004) Role of silicon in enhancing the resistance of plants to biotic and abiotic stresses. Soil Science and Plant Nutrition 50(1): 11-18.

Ma JF, Yamaji N (2006) Silicon uptake and accumulation in higher plants. Trends in Plant Science 11(8): 392$-397$.

Ma JF, Yamaji N (2015) A cooperated system of silicon transport in plants. Trends Plant Science 20: 435-442.

Machado RS, Ribeiro RV, Marchiori PER, Machado DFSP, Machado EC, Landell MA (2009) Respostas biométricas e fisiológicas ao déficit hídrico em cana-deaçúcar em diferentes fases fenológicas. Pesquisa Agropecuária Brasileira 44(12):1575-1582.

Malavolta E (2006). Manual de nutrição de plantas. São Paulo: Agronômica Ceres, 638 p.
Martins APC, Albrecht LP, Castaldo J, Carneiro R, Zucareli V (2015) Novas tecnologias no plantio de canade-açúcar (Saccharum spp). Journal of Agronomic Sciences 4: 301-317.

Matsuoka S (2017) Free Fiber Level Drives Resilience and Hybrid Vigor in Energy Cane. Journal of Scientific Achievements 2: 1-35.

Mauad M, Crusciol CAC, Grassi Filho, H (2011) Produção de massa seca e nutrição de cultivares de arroz de terras altas sob condicão de déficit hídrico e adubação silicatada. Semina: Ciências Agrárias 32(3): 9399ै48. doi: 10.5433/1679-0359.2011v32n3p939

Meena VD, Dotaniya ML, Coumar V, Rajendiran S, Kundu S, Rao AS (2014) A case for silicone fertilization to improve cropyields in tropical soils. Proceedings of the National Academy of Sciences, India Section B: Biological Sciences 84(3): 505-518.

Mellis EV, Quaggio JA, Becari GRG, Teixeira LAJ, Cantarella H, Dias FLF (2016) Effect of Micronutrients Soil Supplementation on Sugarcane in Different Production Environments: Cane Plant Cycle. Agronomy Journal 108:2060-2070. doi:10.2134/agronj2015.0563

Mellis EV, Quaggio JA, Cantarella H (2008) Micronutrientes. In: Dinardo-Miranda LL, Vasconcellos ACM, Landell MGA. (eds) Cana-de-açúcar. Campinas: Instituto Agronômico, p.331-335

Meyer JH, Keeping MG (2001) Past, present and future research of the role of silicon for sugarcane in southern Africa. In: Datnoff LE, Snyder GH, Korndorfer GH (ed) Silicon in Agriculture, Elsevier. p.257-275.

Millaleo M, Reyes-Diaz M, Ivanov AG, Mora ML, Alberdi $M(2010)$ Manganese as essential and toxic element for plants transport, accumulation and resistance mechanisms. Journal of Soil Science and Plant Nutrition 10(4): $\quad 470-481$.doi: $\quad$ 10.4067/S071895162010000200008

Mitani N, Yamaji N, Ma JF (2008) Identification of maize silicon influx transporters. Plant and Cell Physiology 50: 5-12. doi: $10.1093 /$ pcp/pcn110

Mousavi SR, Shahsavari M, Rezaei M (2011) Uma visão geral sobre a importância do manganês $(\mathrm{Mn})$ na produção agrícola. Australian Journal of Basic Applied Sciences 5: 1799-1803

Oliveira KS, Prado RM, Guedes VH (2020) Leaf Spraying of Manganese with Silicon Addition Is Agronomically Viable for Corn and Sorghum Plants. Journal of Soil Science and Plant Nutrition 1: 1-9. doi:10.1007/s42729-020-00173-6

Oliveira RLL de, Prado RM, Felisberto G, Checchio MV, Gratão PL (2019) Silicon Mitigates Manganese Deficiency Stress by Regulating the Physiology and Activity of Antioxidant Enzymes in Sorghum Plants. Journal of Soil Science and Plant Nutrition 19: 524-534. doi: 10.1007/s42729-019-00051-w 
Orlando Filho J (1993) Calagem e adubação da canade-açúcar. In: Câmara GMS, Oliveira EAM (ed). Produção de cana-de-açúcar. Piracicaba, FEALQ 133-46.

Pascual MB, Echevarria V, Gonzalo MJ, HernándezApaolaza L (2016) Silicon addition to soybean (Glycine max L.) plants alleviate zinc deficiency. Plant Physiology and Biochemistry 108: 132-138. doi: 10.1016/j.plaphy.2016.07.008.

Pavlovic J, Samardzic J, Maksimović V, Timotijevic L, Stevic N, Laursen $\mathrm{KH}$, Hansen $\mathrm{TH}$, Husted $\mathrm{S}$, Schjoerring JK, Liang Y, Nikolic M (2013) Silicon alleviates iron deficiency in cucumber by promoting mobilization of iron in the root apoplast. New Phytology 198(4): 1096-1107. doi: 10.1111/nph.12213

Pei ZF, Ming DF, Liu D, Wan GL, Geng XX, Gong HJ, Zhou WJ (2010) silicon improves the tolerance to waterdeficit stress induced by polyethylene glycol in wheat (Triticum aestivum L.) seedlings. Journal of Plant Growth Regulation 29: 106-115. https://doi.org/10.1007/s00344-009-9120-9

Pfeffer PE, Tu S, Gerasimowicz WV, Cavanaugh JR (1986) In vivo 31P NMR studies of corn root tissue and its uptake of toxic metals. Plant Physiology 80: 77-84. doi: $10.1104 / p p .80 .1 .77$

Prado RM (2020) Nutrição de plantas. São Paulo: Editora UNESP, 414p.

Quintana KA, Zanini JR, Silva ER (2012) Irrigação e fertirrigação por gotejamento em cana-de-açúcar na presença e ausência de boro. Científica 40(2): 103-116.

Santos LS, Braga NCC, Rodrigues TM, Rubio Neto A, Brito MF, Severiano, EC (2020) Pre-sprouted seedlings of sugarcane using sugarcane industry by-products as substrate. Sugar Tech 1:1-11. doi: 10.1007/s12355020-00798-y.

Savant NK, Korndorfer GH, Datnoff LE, Snyder GH (1999) Silicon nutrition and sugarcane production: A review. Journal of Plant Nutrition 22: 1853-1903.

Schmidt SB, Jensen PE, Husted S (2016) Manganese deficiency in plants: The impact on photosystem II. Trends in Plant Science 21: 622-632. doi: 0.1016/j.tplants.2016.03.001

Sousa CCM, Pedrosa EMR, Rolim MM, Oliveira Filho RA, Souza MALM, Pereira Filho JV (2015) Crescimento e respostas enzimáticas do feijoeiro caupi sob estresse hídrico e nematoide de galhas. Revista Brasileira de Engenharia Agrícola e Ambiental 19(2): 113-118.

Souza JLMD, Gerstemberger E, Gurski BC, Oliveira RAD (2015) Adjustment of water-crop production models for ratoon sugarcane. Pesquisa Agropecuária Tropical 45(4): 426-433.
Sultanum E (1972) Considerações sobre a sintomatologia de micronutrientes em cana-de-açúcar. Brasil Açucareiro, Rio de Janeiro 83(2): 1-15.

Teixeira GCM, de Mello Prado R, Oliveira KS, D’AmicoDamião V, Sousa Junior GS (2020a) Silicon increases leaf chlorophyll content and iron nutritional efficiency and reduces iron deficiency in sorghum plants. Journal of Soil Science and Plant Nutrition 1: 1-10. https://doi.org/10.1007/s42729-020-00214-0

Teixeira GCM, de Mello Prado R, Rocha AMS, dos Santos LCN, dos Santos Sarah MM, Gratão PL, Fernandes C (2020b) Silicon in pre-sprouted seedlings mitigates the effects of water deficit after transplanting. Journal of Soil Science and Plant Nutrition 1: 1-11. https://doi.org/10.1007/s42729-019-00170-4

Timotiwu B, Nurmauli N, Yulianti P (2017) Application of manganese and silica through leaves and their effect on growth and yield of rice field in village of Sinar Agung, sub-district of Pulau Panggung, district of Tanggamus, Lampung Province, Indonesia. Journal of Agricultural Science 4:48-60.

Tubana BS, Babu T, Datnoff LE (2016) A review of silicon in soils and plants and its role in US agriculture: history and future perspectives. Soil Science 181(9/10): 393-411.

Vandeleur RK, Mayo G, Shelden MC, Gilliham M, Kaiser BN, Tyerman SD (2009) the role of plasma membrane intrinsic protein aquaporins in water transport through roots: diurnal and drought stress responses reveal different strategies between isohydric and anisohydric cultivars of grapevine. Plant Physiology149: 445-460. doi: 10.1104/pp.108.128645

Vasanthi N, Saleena LM, Raj SA, Vijay R, Pvt B (2014) Silicon in crop production and crop protection - a review. Agricultural Research Communication Centre 35:14-23

Xavier MA, Landell MGA, Campana MP, Figueiredo P, Mendonça JR, Dinardo Miranda LL, Scarpari MS, Garcia JC, Anjos IA, Azania CAM, Brancalião SR, Kanthack RAD, Aferri G, Silva DN, Bidóia MAP, Campos MF, Perruco D, Matsuo RS, Neves JCT, Cassaneli Júnior JR, Perruco L, Petri RH, Silva TN, Silva VHP, Thomazinho Júnior JR, Miguel PEM, Lorenzato CM (2013) Fatores de desuniformidade e kit de pré-brotação IAC para sistema de multiplicação de cana-de-açúcar - mudas pré-brotadas (MPB). Ribeirão Preto: Instituto Agronômico de Campinas, p.22. (IAC. Documentos, 113).

Yan G, Nikolic M, Ye M, Xiao Z, Liang Y (2018) Silicon acquisition and accumulation in plant and its significance for agriculture. Journal of Integrative Agriculture 17(10): 2138-2150. doi:10.1016/s20953119(18)62037-4 